\title{
What made the June 2013 flood in Germany an exceptional event? A hydro-meteorological evaluation
}

\author{
K. Schröter ${ }^{1,3}$, M. Kunz ${ }^{2,3}$, F. Elmer ${ }^{1,3}$, B. Mühr ${ }^{2,3}$, and B. Merz ${ }^{1,3}$ \\ ${ }^{1}$ Helmholtz Centre Potsdam, GFZ German Research Centre for Geosciences, Section Hydrology, Potsdam, Germany \\ ${ }^{2}$ Karlsruhe Institute of Technology, Institute for Meteorology and Climate Research, Karlsruhe, Germany \\ ${ }^{3}$ CEDIM - Center for Disaster Management and Risk Reduction Technology, Potsdam, Germany \\ Correspondence to: K. Schröter (kai.schroeter@gfz-potsdam.de)
}

Received: 23 June 2014 - Published in Hydrol. Earth Syst. Sci. Discuss.: 15 July 2014

Revised: - - Accepted: 21 December 2014 - Published: 16 January 2015

\begin{abstract}
The summer flood of 2013 set a new record for large-scale floods in Germany for at least the last 60 years. In this paper we analyse the key hydro-meteorological factors using extreme value statistics as well as aggregated severity indices. For the long-term classification of the recent flood we draw comparisons to a set of past large-scale flood events in Germany, notably the high-impact summer floods from August 2002 and July 1954. Our analysis shows that the combination of extreme initial wetness at the national scale - caused by a pronounced precipitation anomaly in the month of May 2013 - and strong, but not extraordinary event precipitation were the key drivers for this exceptional flood event. This provides additional insights into the importance of catchment wetness for high return period floods on a large scale. The database compiled and the methodological developments provide a consistent framework for the rapid evaluation of future floods.
\end{abstract}

\section{Introduction}

In June 2013, wide parts of central Europe were hit by large-scale flooding. Particularly southern and eastern Germany were affected, but also other countries such as Austria, Switzerland, the Czech Republic, Poland, Hungary, Slovakia, Croatia and Serbia. Almost all main river systems in Germany showed high water levels: the Elbe between Coswig and Lenzen, the Saale downstream of Halle, and the Danube at Passau experienced new record water levels. Severe flooding occurred especially along the Danube and Elbe rivers, as well as along the Elbe tributaries Mulde and Saale. In the Weser and Rhine catchments exceptional flood magnitudes were, however, observed only locally in some smaller tributaries. The area affected most in the Rhine catchment was the Neckar with its tributaries Eyach and Starzel. In the Weser catchment the Werra sub-catchment was affected most - in particular the discharges in the Hasel and Schmalkalde tributaries were on an exceptional flood level (BfG, 2013). As a consequence of major dike breaches at the Danube in Fischerdorf near Deggendorf, at the confluence of the Saale and Elbe rivers at Rosenburg, and at the Elbe near Fischbeck, large areas were inundated with strong impacts on society in terms of direct damage and interruption of transportation systems (see Fig. A1 in the Appendix for geographic locations).

Estimates on overall losses caused by the flooding in central Europe are in the range of EUR 11.4 (Munich Re, 2013) to 13.5 billion (Swiss Re, 2013), whereof EUR 10 billion occurred in Germany alone. Official estimates of economic loss for Germany amount to EUR 6.6 billion (Deutscher Bundestag, 2013) with an additional EUR 2 billion of insured losses (GDV, 2013). These numbers are about $60 \%$ of the total loss of EUR 14.1 billion (normalized to 2013 values) in Germany caused by the extreme summer flood in August 2002 (Kron, 2004; Thieken et al., 2005) which remains the most expensive natural hazard experienced in Germany so far.

The June 2013 flood was an extreme event with regard to magnitude and spatial extent as well as its impact on society and the economy (Blöschl et al., 2013; Merz et al., 2014). The Forensic Disaster Analysis (FDA) Task Force of the Centre for Disaster Management and Risk Reduction Technology (CEDIM) closely monitored the evolution 
of the flood in June 2013 including the impacts on people, transportation and economy in near real time. In this way CEDIM made science-based facts available for the identification of major event drivers and for disaster mitigation. The first phase of this activity was done by compiling scattered information available from diverse sources including in situ sensors and remote sensing data, the internet, media and social sensors as well as by applying CEDIM's own rapid assessment tools. Two reports were issued: the first report focused on the meteorological and hydrological conditions including comparisons to major floods from the past (CEDIM, 2013a), while the second one focused on impact and management issues (CEDIM, 2013b).

The subsequent phase of this FDA activity focused on the research question: what made the flood in June 2013 an exceptional event from a hydro-meteorological point of view? This question is analysed in this paper. We expect this analysis to improve the understanding of key drivers of large-scale floods and thus contribute to the derivation of well-founded and plausible extreme scenarios.

In this context, the statement of BfG (2013) and Blöschl et al. (2013) that high initial soil moisture played an important role for the generation of this extreme flood are an interesting starting point. Klemes (1993) reasoned that high hydrological extremes are more due to unusual combinations of different hydro-meteorological factors than to unusual magnitudes of the factors themselves. On the one hand, catchment wetness state is an important factor for the generation of floods (Merz and Blöschl, 2003). As such it is a useful indicator in flood early warning schemes (e.g. Van Steenbergen and Willems, 2013; Alfieri et al., 2014; Reager et al., 2014) and is also incorporated in procedures for extreme flood estimation (e.g. Paquet et al., 2013). On the other hand the contribution of catchment wetness to extreme floods has been shown to be of decreasing importance with increasing return periods of rainfall (e.g. Ettrick et al., 1987; Merz and Plate, 1997). However, the interaction of various hydro-meteorological factors, primarily rainfall and soil moisture, has been studied mainly for small-scale catchments (e.g. Troch et al., 1994; Perry and Niemann, 2007). Only few studies examined the interplay of various hydro-meteorological factors for large-scale floods. One example is the work of Nied et al. (2013) who investigated the role of antecedent soil moisture for floods in the Elbe catchment (ca. $150000 \mathrm{~km}^{2}$ ) and emphasized the increased occurrence probability of large-scale floods related to large-scale high soil moisture.

In this study, we examine key meteorological and hydrological characteristics of the June 2013 flood and compare them to two other large-scale high-impact events, the August 2002 and July 1954 floods in Germany. The factors considered are antecedent and event precipitation, initial streamflow conditions in the river network and flood peak discharges. We evaluate these factors in a long-term context in terms of recurrence intervals using extreme value statistics based on a 50-year reference period. For this period the set of large-scale floods in Germany identified by Uhlemann et al. (2010) are updated and now comprises 74 flood events. Hence, the analysis is deliberately limited to the national borders of Germany in order to be able to compare the 2013 flood with the event set of Uhlemann et al. (2010). For a coherent comparison of the events we use available long-term data sets of precipitation and discharge observations. Besides the statistical analysis we derive different indices to rank the spatial extent and magnitude of the hydro-meteorological factors.

The spatial extent and hydrological severity of largescale floods in Germany has been analysed by Uhlemann et al. (2010) in terms of flood peak discharges using a specifically developed flood severity index. In our study we enhance this framework to include antecedent and event precipitation as well as initial streamflow as additional hydrometeorological factors. We introduce severity indices for these factors to evaluate their relative importance among the event set. Precipitation and flood peak discharges are key figures which are commonly used to characterize cause and effect of floods. The antecedent precipitation index is a well-established parameter to approximate catchment wetness (Teng et al., 1993; Ahmed, 1995). Even though there are reasonable objections against API as it disregards soil and land use characteristics which influence soil hydrological processes, it provides sufficient information to compare the potential wetness between different large-scale floods. Initial streamflow is usually not considered in hydrological analyses of flood events but is a very relevant factor for dynamic flood routing processes (Chow, 1959) as it controls the load of a river section. The inclusion of this factor within a statistical analysis of large-scale flood events is, to the knowledge of the authors, done for the first time.

The paper is organized as follows. Section 2 describes the data and methods used to conduct the hydro-meteorological analysis of the June 2013 flood and the set of large-scale flood events. Section 3 describes the meteorological situation associated with the flood in June 2013 and presents the results from the analysis of antecedent and event precipitation, initial river flow conditions and flood peak discharges. Detailed comparisons with the extreme summer floods of $\mathrm{Au}-$ gust 2002 and July 1954 are made. The section concludes with a sensitivity analysis of the procedure. In Sect. 4 we discuss the key findings and provide recommendations for future work. A map of geographical locations mentioned in the paper can be found in the Appendix as well as some additional information regarding sensitivities. 
Table 1. Data sources, resolution and analysis methods for hydro-meteorological parameters.

\begin{tabular}{|c|c|c|c|c|c|}
\hline \multicolumn{2}{|c|}{ Hydro-meteorological factors } & \multirow{3}{*}{$\begin{array}{l}\text { Data source } \\
\text { REGNIE DWD }^{1}\end{array}$} & \multirow{3}{*}{$\begin{array}{l}\text { Spatial } \\
\text { resolution }\end{array}$} & \multirow{2}{*}{$\begin{array}{l}\text { Temporal } \\
\text { resolution }\end{array}$} & \multirow{2}{*}{$\begin{array}{l}\text { Analysis/classification } \\
\text { Maximum } 3 \text { day totals R3d. } \\
\text { extreme value statistics based on } \\
\text { annual series }\end{array}$} \\
\hline Precipitation & & & & & \\
\hline & & & & $\begin{array}{l}\text { Event- } \\
\text { based }\end{array}$ & $\begin{array}{l}\text { Precipitation index for all } \\
\text { large-scale floods }\end{array}$ \\
\hline \multirow[t]{4}{*}{ Initial catchment state } & $\begin{array}{l}\text { Antecedent } \\
\text { precipitation index } \\
\text { API }\end{array}$ & REGNIE DWD $^{1}$ & $1 \mathrm{~km}^{2}$ & Daily & $\begin{array}{l}\text { API quantification } 30 \text { days ahead of } \\
\text { R3d; extreme value statistics based } \\
\text { on partial series conditional on past } \\
\text { flood events }\end{array}$ \\
\hline & & & & $\begin{array}{l}\text { Event- } \\
\text { based }\end{array}$ & $\begin{array}{l}\text { Wetness index for all past flood } \\
\text { events }\end{array}$ \\
\hline & $\begin{array}{l}\text { Ratio of initial } \\
\text { river flow to mean } \\
\text { annual flood }\end{array}$ & $\begin{array}{l}\text { Discharge gauges } \\
\mathrm{BfG}^{2} / \mathrm{WSV}^{3} \text { and } \\
\text { hydrometric services } \\
\text { of federal states }\end{array}$ & $\begin{array}{l}\text { Point information; } \\
162 \text { gauges and } \\
\text { related sub-basins }\end{array}$ & Daily mean & $\begin{array}{l}\text { Extreme value statistics based on } \\
\text { partial series conditional on past } \\
\text { flood events }\end{array}$ \\
\hline & & & & $\begin{array}{l}\text { Event- } \\
\text { based }\end{array}$ & $\begin{array}{l}\text { Initial hydraulic load index for all } \\
\text { past flood events }\end{array}$ \\
\hline \multirow{2}{*}{\multicolumn{2}{|c|}{ Peak flood discharge }} & $\begin{array}{l}\text { Discharge gauges } \\
\mathrm{BfG}^{2} / \mathrm{WSV}^{3} \text { and } \\
\text { hydrometric services } \\
\text { of federal states }\end{array}$ & $\begin{array}{l}\text { Point information; } \\
162 \text { gauges and } \\
\text { related sub-basins }\end{array}$ & Daily mean & $\begin{array}{l}\text { Extreme value statistics based on } \\
\text { annual maximum series }\end{array}$ \\
\hline & & & & $\begin{array}{l}\text { Event- } \\
\text { based }\end{array}$ & $\begin{array}{l}\text { Flood severity index for all past } \\
\text { flood events }\end{array}$ \\
\hline
\end{tabular}

${ }^{1}$ German Weather Service; ${ }^{2}$ German Federal Institute of Hydrology; ${ }^{3}$ Water and Shipment Administration.

\section{Data and methods}

\subsection{Data}

\subsubsection{Database of large-scale floods}

For the analysis of the meteorological and hydrological conditions prior to and during large-scale flood events in Germany and their relation to the climatological context, a consistent database of precipitation and discharge data was compiled. For this, we considered a set of large-scale floods which had been first determined in a consistent way by Uhlemann et al. (2010) for the period from 1952 to 2002. In this study, we used an updated event set from 1960 to 2009. These flood events are identified from daily mean discharge records at 162 gauges in Germany by screening these time series for the occurrence of peak discharges above a 10-year flood and significant flood peaks at other gauges within a defined time window that accounts for the time shift between hydraulically coherent peak flows. According to Uhlemann et al. (2010), large-scale floods are characterized by a spatial extent of mean annual flooding which affects at least $10 \%$ of the river network considered in Germany. Applying this criterion, 74 large-scale floods are identified in the reference period 1960-2009. For each flood we derive consistent samples for hydro-meteorological factors including antecedent and event precipitation, initial streamflow conditions and peak discharges. A compilation of hydro-meteorological factors and related data sources, their spatial and temporal resolution, and the methods applied is presented in Table 1.

\subsubsection{Meteorological data sets}

For the triggering of large-scale floods the amount and spatial variability of precipitation are more important than the small-scale temporal variability. For this reason, we used $24 \mathrm{~h}$ precipitation sums of REGNIE (regionalized precipitation totals) both for the reference period 1960-2009 and for the single events 2013 (April-June) and 1954 (June-July). The data set, compiled and provided by the German Weather Service (Deutscher Wetterdienst, DWD), is interpolated from climatological stations to an equidistant grid of $1 \times 1 \mathrm{~km}^{2}$. The interpolation routine considers several geographical factors such as altitude, exposition or slope by distinguishing between background monthly climatological fields and daily anomalies (see Rauthe et al., 2013 for further details). In cases of convective or orographic precipitation, where a very high density of stations is required, it can be expected that REGNIE underestimates the actual spatial variability of precipitation. However, since large-scale flood events are mainly driven by advective precipitation, this effect is of minor importance in the present study. Additionally, weather charts and sounding data are used to describe the characteristics of the atmosphere on the days with maximum rainfall. 


\subsubsection{Hydrological data sets}

We use time series of daily mean discharges from 162 gauging stations operated by the water and shipment administration (WSV), the German Federal Institute of Hydrology (BfG) or by hydrometric services of the federal states. The same selection of gauges has been used by Uhlemann et al. (2010) to compile the set of large-scale flood events in Germany. These gauges have provided continuous records since 1952 and have a drainage area larger than $500 \mathrm{~km}^{2}$. Basin areas vary from $521 \mathrm{~km}^{2}$ to $159300 \mathrm{~km}^{2}$ with a median of $3650 \mathrm{~km}^{2}$ including a high percentage of nested catchments. For the flood in June 2013 raw data of daily mean discharges were available for 121 gauges mainly covering the central, southern and eastern parts of Germany which have been affected most by flooding.

Based on the procedure proposed by Uhlemann et al. (2010), the point observations of discharge peaks at the 162 gauges are regionalized to represent the flood situation in a particular river stretch and its associated catchment area. The regionalization scheme uses the location of the gauges and the hierarchical Strahler order (Strahler, 1957) which accounts for the branching complexity of the river network. A gauge is assumed as representative for an upstream river reach until the next gauge and/or the Strahler order of the river stretch decreases by two orders. In the downstream direction, a gauge is representative until the Strahler order of the river changes by one order or a confluence enters the river which has the same Strahler order or one order smaller. The total length of the river network considered amounts to $13400 \mathrm{~km}$.

\subsection{Methods}

For the statistical analysis of the hydro-meteorological factors and their consistent comparison within the set of largescale flood events, a clear event definition including its onset and duration is required. The start of an event determines the point in time for which we evaluate the different hydro-meteorological factors instantaneously (e.g. initial streamflow) forward (event precipitation, peak discharges) and backward in time (antecedent precipitation). Due to temporal dynamics of the precipitation fields across Germany, flood triggering precipitation affects different catchment areas at different days. Therefore, we do not consider a fixed event start date for the whole of Germany, but one that may vary in space and time, that is, from one grid point to another or from one sub-catchment to another, respectively.

\subsubsection{Definition of event start dates}

We considered two different definitions of the event start date. The first one is related to the onset of the large-scale floods compiled in the event set by Uhlemann et al. (2010). It considers the flood response in the spatial series of mean daily discharges recorded at 162 gauges in Germany taking significant hydraulically coherent peak flows into account. The second is based on the maximum precipitation that triggers the floods. For this we quantify the highest 3-day precipitation totals (R3d) at each REGNIE grid point within a centred 21-day time window that spans from 10 days ahead to 10 days after the event start of a large-scale flood. The duration of the chosen time window considers the time lag which links flood-triggering precipitation with discharge response (e.g. Duckstein et al., 1993) and the travel times of flood waves along the river-course (e.g. Uhlemann et al., 2010). Considering the R3d totals excludes local-scale convective precipitation, which is relevant for local or flash floods but not for large-scale floods (Merz and Blöschl, 2003).

\subsubsection{Event precipitation}

The first day of the R3d period defines the meteorological event start for a given grid point. Depending on the spacetime characteristics of the precipitation fields, these days will be more or less correlated for adjoined grid points. We have performed this analysis for maximum precipitation totals of 3 to 7 days duration and found that this variation does not imply considerable changes in the meteorological event start date. As shown in Fig. A2 in the Appendix the spatial pattern of the 7-day totals do not differ largely from the R3d patterns for the flood events investigated. Therefore we use R3d as a reasonable figure for the meteorological start date of event precipitation.

For the statistical evaluation of event precipitation, annual maximum 3-day precipitation totals are determined for the reference period from 1960 to 2009 and for the two events of 1954 and 2013. Using extreme value statistics, return periods are determined for the event-triggering R3d totals independently for each grid point.

\subsubsection{Antecedent precipitation}

The meteorological event starts (first day of maximum R3d) are used to calculate antecedent precipitation backward in time. We use the antecedent precipitation index (API) according to Köhler and Linsley (1951) as a proxy for the wetness conditions in a catchment in the period before the event precipitation. The relation between surface soil moisture content and different versions of the API was shown, for instance by Blanchard et al. (1981) or Teng et al. (1993). We quantify API over a 30-day period prior to the meteorological event start dates at each grid point for each event of the largescale flood set. API is given by the sum of daily precipitation weighted with respect to the time span (here: $m=30$ days) of rainfall occurrence before the reference day:

$\operatorname{API}(x, y)=\sum_{i=1}^{30} k^{i} R_{i}(x, y)(m-i)$, 
where $R_{i}(x, y)$ is the $24 \mathrm{~h}$ total at a specific grid point $(x, y)$ and $i$ represents the day prior to the 3-day maximum, which ensures that event precipitation and antecedent precipitation are clearly separated. Usually a value between 0.8 and 0.98 is used for the depletion constant $k$ (Viessman and Lewis, 2002). The potentiation of $k$ with the number of days $i$ assigns continuously decreasing weights to rainfall that occurred earlier. This relation approximates the decrease of soil moisture due to evapotranspiration and percolation to deeper soil layers. In our study we selected a mean value of $k=0.9$. For the statistical analysis of API and thus the calculation of return periods we use partial series which are derived using the meteorological event start dates identified for the 74 large-scale flood events in the period 1960-2009.

\subsubsection{Precipitation and wetness indices}

To further evaluate the importance of the hydrometeorological factors R3d and API and to rank their spatial extent and magnitude for the floods in June 2013, August 2002 and July 1954 among the set of large-scale floods we introduce precipitation and wetness severity indices as aggregated measures:

$S_{X}^{k}=\frac{1}{\Gamma} \sum_{i, j}\left\{\frac{X_{i, j}^{k}}{X_{i, j}^{5 \mathrm{yr} \mathrm{RP}}}\right\} \mid X_{i, j}^{k} \geq X_{i, j}^{5 \mathrm{yr} \mathrm{RP}}$,

where $X$ is either R3d or API and $5 \mathrm{yr}$ RP denotes the values for a 5-year return period. In this formulation, values of R3d and API, respectively, are considered at REGNIE grid points $i, j$ that exceed the 5 -year return values. For each event $k$ the sum of the ratios of R3d and API to the 5-year return period are normalized with the mean area size $\Gamma$ represented by the total number of REGNIE grid points in Germany.

\subsubsection{Initial hydraulic load}

To transfer the meteorological event start dates, possibly varying from grid cell to grid cell, to the discharge time series given at gauge locations, we need to spatially integrate and hence to average the event start dates for individual grid points within hydrological sub-basins. We use the subcatchments of the 162 river gauges as spatial units. The resulting "areal mean" dates per sub-catchment are used as the event start date for the hydrological analyses.

The streamflow situation at the beginning of the flood event provides information on the initial hydraulic load of the river cross-section. An already increased discharge level may considerably strain the discharge capacity of a river section, and thus the superposition of the subsequent flood wave may increase the load on flood protection schemes and may aggravate inundations. For the statistical analysis of the initial streamflow conditions, we normalize the discharge values by calculating the ratio of the daily mean discharge on the event start date $\left(Q_{\mathrm{i}}\right)$ and the mean annual flood $(\mathrm{MHQ}=$ mean of annual maximum discharges) for each of the $n=162$ gauges. For each gauge a partial series is created by evaluating the ratio of $Q_{\mathrm{i}}$ and MHQ for the areal mean event start dates in the corresponding sub-catchment which are derived using the meteorological event start dates identified for the 74 large-scale flood events in the period 1960-2009.

Further, we introduce an initial load severity index representing the spatially weighted sum of the initial hydraulic load level in the river network for each event $k$ :

$S_{Q_{\mathrm{i}}}^{k}=\sum_{n}\left\{\lambda_{n} \cdot\left(\frac{Q_{\mathrm{i}}}{\mathrm{MHQ}}\right)_{n}\right\} \mid\left(\frac{Q_{\mathrm{i}}}{\mathrm{MHQ}}\right)_{n} \geq\left(\frac{Q_{\mathrm{i}}}{\mathrm{MHQ}}\right)_{n}^{5 \text { yr RP }}$,

where 5-yr RP denotes the flow ratio with a 5-year return period and the weights $\lambda_{n}$ correspond to the ratio of the river stretch length $\left(l_{n}\right)$ associated with a certain gauge and the total length of the river network: $\lambda_{n}=\frac{l_{n}}{\sum_{n} l_{n}}$.

\subsubsection{Peak discharge}

Peak discharge $\left(Q_{\mathrm{p}}\right)$ is a key figure to characterize the magnitude of a flood at a specific location. $Q_{\mathrm{p}}$ is the integrated outcome of hydrological and hydraulic processes upstream of that location and provides important information for numerous water resources management issues in particular flood estimation and flood design. For the statistical evaluation of the observed flood peaks at each of the 162 gauges we use the annual maximum series (AMS) of daily mean discharges. We evaluate the spatial flood extent and magnitude using an aggregated measure of event severity. For this purpose we calculate the length of the river network $L$ for which during event $k$ the peak discharge $Q_{\mathrm{p}}$ exceeds the 5-year return period:

$L^{k}=\sum_{n}\left\{\lambda_{n} \cdot 100\right\} \mid Q_{\mathrm{p}_{n}}^{k} \geq Q_{\mathrm{p}_{n}}^{5 \mathrm{yr} \mathrm{RP}}$,

where 5-yr RP denotes the discharge with a 5 year return period and the weights $\lambda n$ are defined as explained above. The flood severity index represents a weighted sum of peak discharges $Q_{\mathrm{p}}$ normalized by a 5 -year flood using $\lambda n$ as weights:

$S_{Q_{\mathrm{p}}}^{k}=\sum_{n}\left\{\lambda_{n} \cdot \frac{Q_{\mathrm{p}_{n}}^{k}}{Q_{\mathrm{p}_{n}^{5}}^{5 \mathrm{yrRP}}}\right\} \mid Q_{\mathrm{p}_{n}}^{k} \geq Q_{\mathrm{p}_{n}}^{5 \mathrm{yr} \mathrm{RP}}$.

\subsubsection{Extreme value statistics}

To calculate exceedance probabilities and return periods $(\mathrm{Tn})$ for the various hydro-meteorological factors, i.e. R3d, API, $Q_{\mathrm{i}} / \mathrm{MHQ}$ and $Q_{\mathrm{p}}$, observed for the June 2013, August 2002 and July 1954 floods, we applied the classical generalized extreme value distribution (Embrechts et al., 1997). Most appropriate and widely used in the case of precipitation is the Fisher-Tippett type I extreme value distribution, also known 

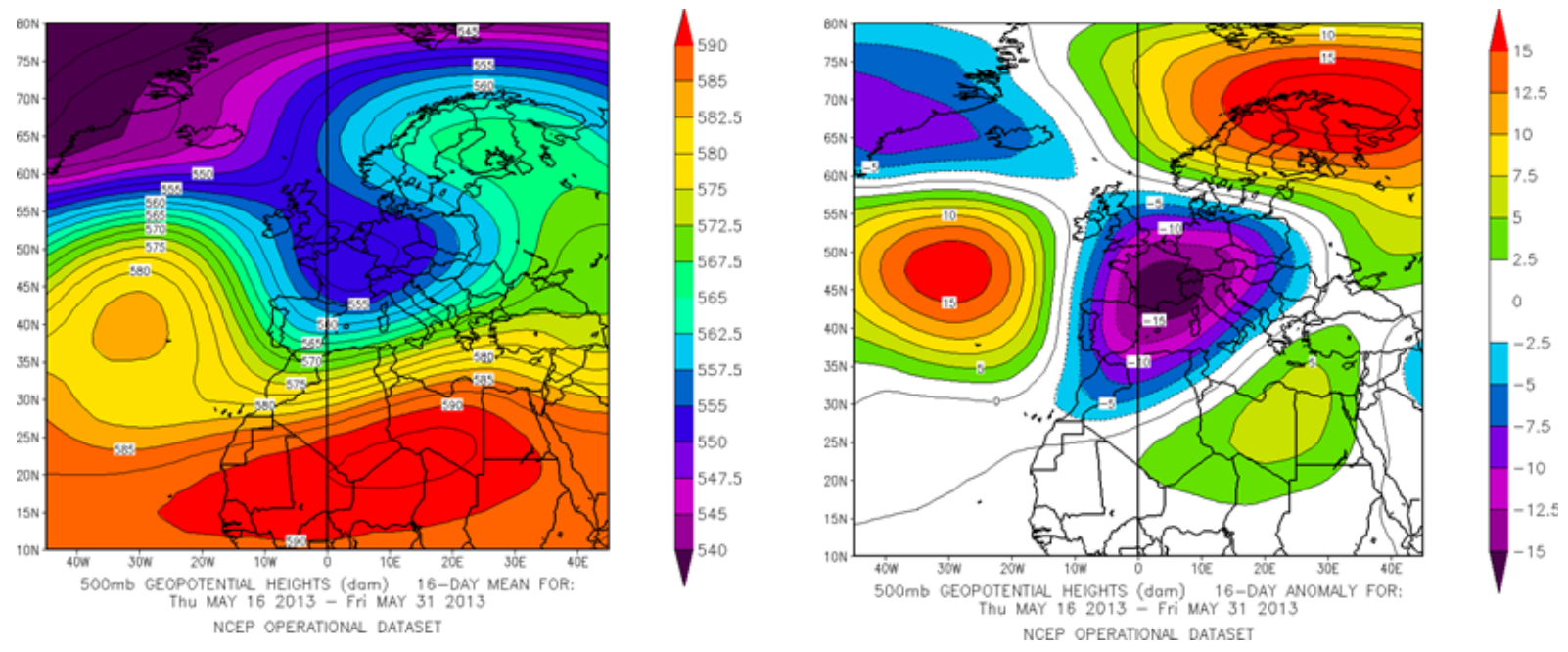

Figure 1. $500 \mathrm{hPa}$ geopotential height, 16 day mean for 16-31 May 2013 (left) and anomaly in respect to the climatology based on 19791995 (right). Credit: Data/image provided by the NOAA/OAR/ESRL PSD, Boulder, CO, USA, from their Web site at http://www.esrl.noaa. gov/psd/ (last access: 4 April 2014).

as Gumbel distribution, with a cumulative distribution function $(\mathrm{CDF})$ of

$$
F(x)=\exp \left[-\exp \left(-\frac{x-\beta}{\alpha}\right)\right],
$$

where $\alpha$ is the scale parameter affecting the extension in the $x$-direction and $\beta$ is the mode that determines the location of the maximum. This distribution is also suitable for the $Q_{\mathrm{i}} / \mathrm{MHQ}$ samples. For the statistical analysis of $Q_{\mathrm{p}}$ we fit a generalized extreme value distribution to the AMS of daily mean discharges. The CDF of the generalized extreme value distribution has a function of

$$
F(x)=\exp \left\{-\left[1+\frac{\gamma(x-\zeta)}{\delta}\right]^{-1 / \gamma}\right\},
$$

where $\delta$ is the scale parameter affecting the extension in the $x$-direction, $\zeta$ is a location parameter and $\gamma$ is a shape parameter.

\section{Results}

\subsection{Meteorological conditions}

Large-scale central European floods are mainly caused by the interaction of upper-level pressure systems, associated surface lows and the continuous advection of moist and warm air over long distances. In 2013, the second half of the month of May was exceptionally wet across most of central Europe due to the unusual persistence of an extended upperair low-pressure system (trough; Fig. 1, left) that triggered several surface lows. The persistence of the quasi-stationary trough is reflected by a strong negative geopotential anomaly compared to the long-term mean (1979-1995) over France, Switzerland and northwestern Italy (Fig. 1, right). This trough was flanked by two upper-air high-pressure systems over northeastern Europe and the North Atlantic Ocean, which caused a blocking situation. Therefore, Atlantic air masses from the west were prevented from entering central Europe. On the other side, warm and humid air masses were repeatedly advected from southeastern Europe northwards and eventually curved into Germany and Austria.

The intense and widespread rain that finally triggered the 2013 flood occurred at the end of May/ beginning of June. Responsible for the heavy rainfall was a cut-off low that moved slowly with its centre from France (29 May) over northern Italy (30 May; Fig. 2a) to Eastern Europe (1 June; Fig. 2b). In the latter region, three consecutive surface lows were triggered by short-wave troughs that travelled around the cut-off low (CEDIM, 2013a). On the northeastern flank of the upper low and near the secondary surface lows, warm and moist air masses were advected into central Europe. Grams et al. (2014) identified evapotranspiration from continental landmasses of central and Eastern Europe as the main moisture source. Due to the significant horizontal pressure gradient in the lower troposphere that prevailed from the end of May to the first days of June, there was a constant and strong northerly flow of moist and warm air which caused substantial rain enhancement on the northern side of the west-to-east oriented mountain ranges, e.g. the Alps, Ore Mountains and Swabian Jura.

In summary, the combination of large-scale lifting at the downstream side of the troughs, orographically induced lifting over the mountains, and embedded convection in the mainly stratiform clouds due to unstable air masses resulted in prolonged and widespread heavy rainfall. 

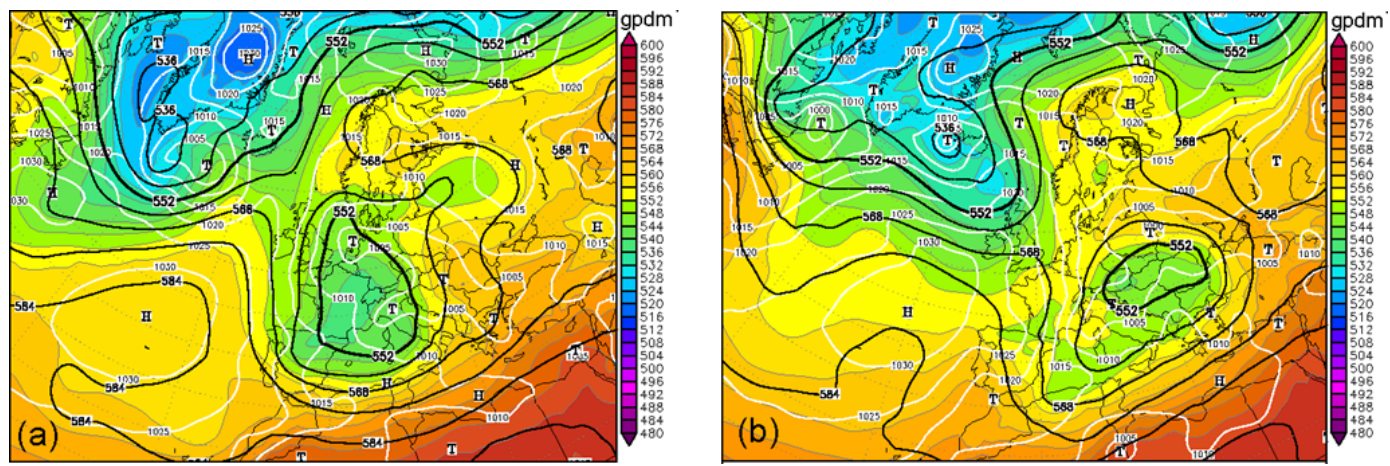

Figure 2. Weather charts for 30 May (a) and 1 June 2013 (b) 00:00 UTC with analysis of $500 \mathrm{hPa}$ geopotential height (black lines), surface pressure (white lines) and 1000/500 hPa relative topography (colours) from the Global Forecast System (GFS). Image credit: wetter3.de (last access: 7 May 2014).
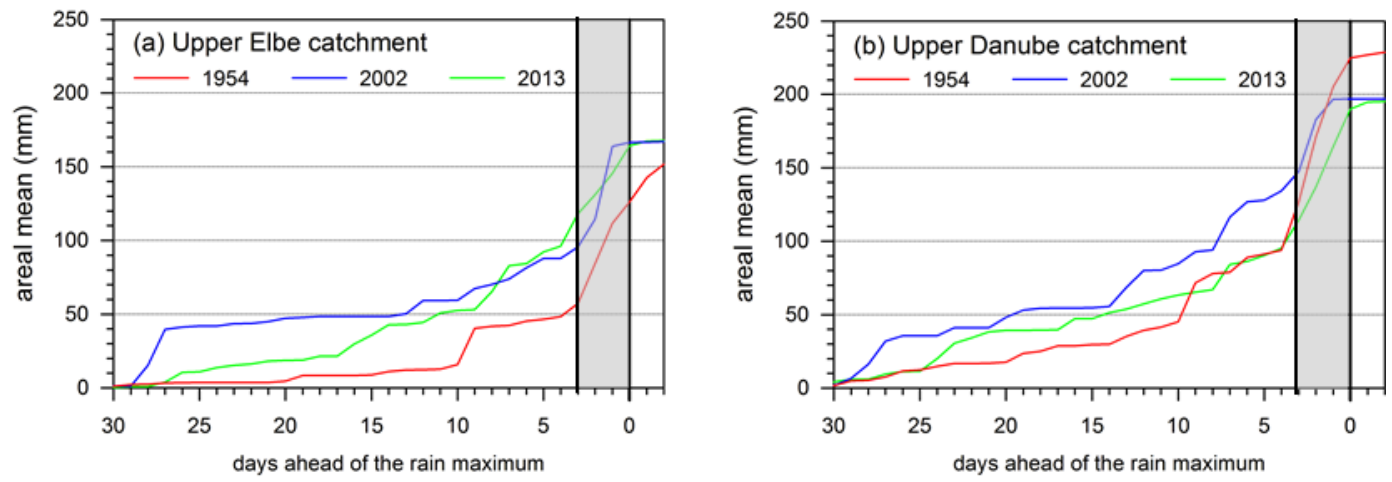

Figure 3. Time series of cumulated areal mean precipitation for the upper Elbe catchment in Germany up to the inflow of the Saale River (a) area: $63171 \mathrm{~km}^{2}$ ) and for the upper Danube catchment in Germany (b; area: $51379 \mathrm{~km}^{2}$ ). The $x$-axis marks the days prior to the 3-day maximum precipitation totals. Event precipitation is highlighted in grey.

\subsection{Precipitation}

Highest precipitation totals within the 30-day period prior to the flood event start dates can be observed between 3 and 4 days ahead of the flood event start date (indicated by the zero in Fig. 3), as shown by the time series of cumulated areal precipitation averaged over the upper Elbe (Fig. 3a) and Danube (Fig. 3b) catchments. Note that these characteristics are almost the same for the other two floods considered, 2002 and 1954, respectively. Especially for the Elbe catchment in May 2013, rain totals were high up to 17 days prior the event start, and higher compared to the other events (if the large totals 28 days ahead of the 2002 flooding are neglected). For the whole month of May 2013, the precipitation averaged over Germany was $178 \%$ of the long-term average for the period 1881-2012 (DWD, 2013). To better explain differences and similarities of the three flood events considered, we analysed both maximum 3-day precipitation totals (R3d) as event precipitation and precipitation in the month before the flooding in terms of API. In both cases, the quantities are calculated independently at each grid point of the REGNIE gridded precipitation data (see Sect. 2.2).

\subsubsection{Event precipitation}

Maximum 3-day totals (R3d) in 2013 show high values in excess of $60 \mathrm{~mm}$ over southern and eastern Germany (Fig. 4, left). The highest rain maximum with $\mathrm{R} 3 \mathrm{~d}=346 \mathrm{~mm}$ was observed at the DWD weather station of Aschau-Stein (31 May-3 June 2013, 06:00 UTC), which is situated in the Bavarian Alps at an elevation of $680 \mathrm{~m}$ a.s.l. This station also recorded the maximum $24 \mathrm{~h}$ rain sum of $170.5 \mathrm{~mm}$ on 1 June 2013 (from 1 June 06:00 UTC until 2 June 2013 06:00 UTC). On that day, peak rainfall was recorded at many other stations in the federal states of Bavaria, Saxony and BadenWürttemberg. Overall, the R3d maxima were registered almost homogeneously between 30 May and 1 June 2013 (Julian day 152, Fig. 5 left). At the upper reaches of Danube and Elbe (German part) the maxima occurred 1 day later. Over the very eastern parts, especially near Dresden and Passau, the temporal difference was even 2 days. This consecutive shift of the main precipitation fields in the west-to-east direction, i.e. following the flow direction of the Danube, caused an additional amplification of the high-water peaks. 

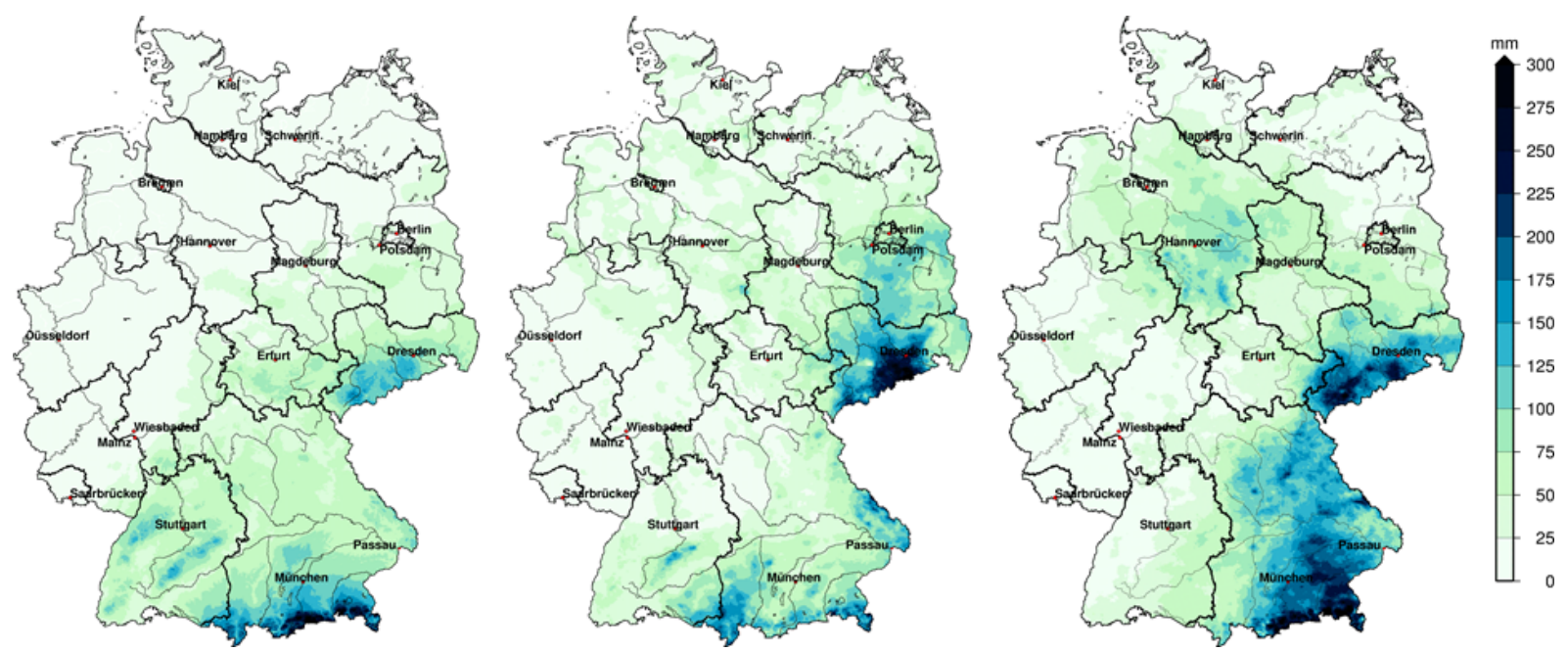

Figure 4. The 3-day maximum precipitation according to REGNIE data sets for June 2013 (left), August 2002 (middle) and July 1954 (right).
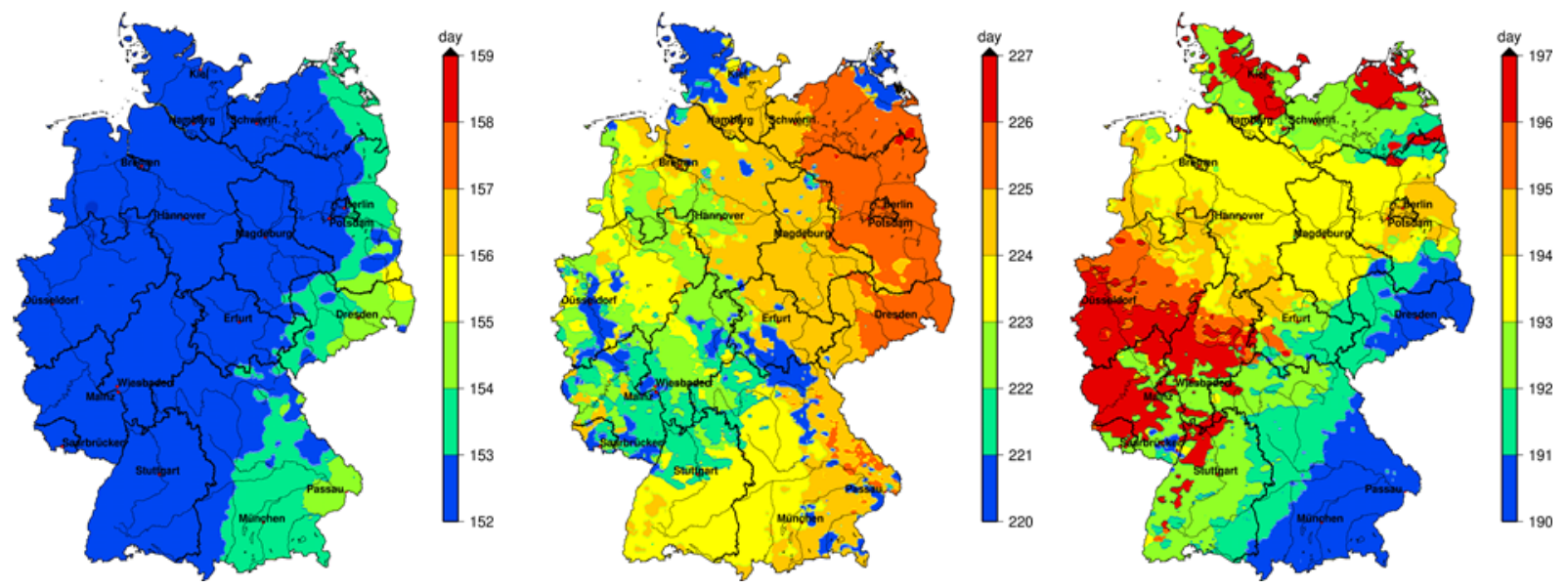

Figure 5. Day of the year at each REGNIE grid point where the event related maximum R3d total according to Fig. 4 occurred (end of the 3-day total) for June 2013 (left), August 2002 (middle) and July 1954 (right). The day 152 corresponds to 1 June, 220 to 8 August, and 190 to 9 July. The indicated days refer to the end of R3d.

Even if the flood-related rainfall in 2013 was mainly driven by meso-scale processes such as uplift related to the troughs and advection of moist air masses, the R3d map suggests that additional orographically induced lifting over the mountains increased the rain totals substantially. Highest rain sums occurred along the crests of the Ore Mountains (near Dresden), the Black Forest and Swabian Jura (west and east of Stuttgart, respectively), the Alpine foothills (south of Munich) and the Bavarian Alps. Overall, the rain enhancement over the low-mountain ranges estimated from the ratio between areal rainfall over the mountains and adjacent lowlands was between 200 and $310 \%$. This substantial localscale increase in precipitation can be plausibly explained by the characteristics of the air mass on the large scale. First of all, the lifting condensation level (LCL), which represents the level of the cloud base in the case of synoptic-scale or orographic lifting, was very low on the first 3 days of June as observed at the sounding stations at Munich, Stuttgart, Meiningen and Kümmersbruck. The pressure levels were only around $920 \mathrm{hPa}$, i.e. near the surface (e.g. at Kümmersbruck the LCL was on average $924.7 \mathrm{hPa} / 765 \mathrm{~m}$ a.s.l). A low LCL ensures that a large amount of atmospheric moisture, which decreases almost exponentially with elevation, basically can be converted into rain. Furthermore, precipitable water $(\mathrm{pw})$ - as the vertical integral of the specific water vapour content - was large, with values of up to $26 \mathrm{~mm}$. The sounding at Stuttgart, for example, measured a pw value of $25.9 \mathrm{~mm}$ (1 June 2013, 12:00 UTC), which is even above the $90 \%$ percentile $\left(\mathrm{pw}_{90}=23.7 \mathrm{~mm}\right)$ obtained from all heavy precipitation events between 1971 and 2000 at the same station according to the study of Kunz (2011). Together with high horizontal wind speeds between 20 and 

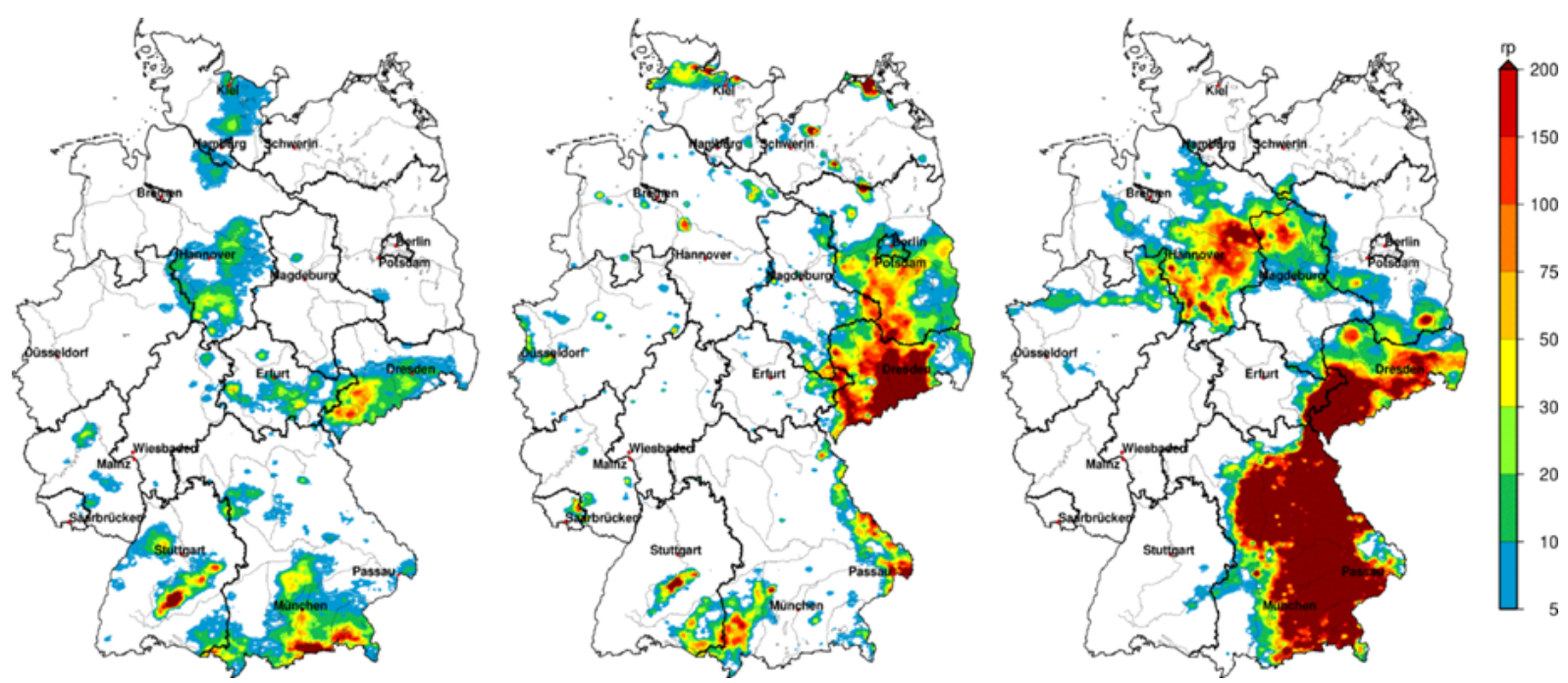

Figure 6. Return periods of 3-day maximum precipitation for each REGNIE grid point derived from data of the period from 1960 to 2009 for the corresponding rain totals displayed in Fig. 4: June 2013 (left), August 2002 (middle), and July 1954 (right).

$75 \mathrm{~km} \mathrm{~h}^{-1}$ (850 $\mathrm{hPa}$; around $1500 \mathrm{~m}$ a.s.l.) this led to a substantial increase of the incoming water vapour flux $\left(F_{\mathrm{wv}}\right)$. This quantity can be considered as an upper limit of the conversion of moisture into precipitation (Smith and Barstad, 2004; Kunz, 2011) Thus, the high $F_{\mathrm{wv}}$ values observed during the first days of June 2013 plausibly explain the substantial orographic rainfall enhancement over the mountains.

To relate the June 2013 precipitation event to the climatological context, we quantify statistical return periods based on REGNIE data for the period from 1960 to 2009. In Fig. 6 (left), the return periods are displayed only in the range between 5 and 200 years. The estimated values of the return periods have been truncated to 200 years as statistical uncertainty substantially increases for larger return periods due to the short observation period of 50 years. Over the southwestern parts of the Ore Mountains, the Swabian Jura and the very southern border of Bavaria, the return periods are in the range between 5 and 20 years. Only a limited number of grid points show peak values in excess of 100 or even 200 years, for example the aforementioned station of Aschau-Stein. Thus, one can conclude that the rainfall was unusually but not extraordinarily high, and hence cannot fully explain the dimension of the 2013 flood.

The most important rainfall characteristics that were decisive for the 2013 flood can be summarized as: (i) high but not extraordinary - 3-day totals over parts of the Danube and Elbe catchments; (ii) substantial rainfall increase over the mountains that was decisive for the onset of the flooding; and (iii) areal precipitation occurring almost simultaneously with a slight temporal shift of 2 days between the western and eastern parts of Germany.

These meteorological conditions differ largely from those prevailing during the floods in 2002 and 1954. Areal 3-day rain totals averaged over the upper Elbe catchment (Germany only, upstream of the confluence of Elbe and Saale) were $49.3 \mathrm{~mm}$ compared to $75.9 \mathrm{~mm}$ in 2002 and $68.8 \mathrm{~mm}$ in 1954 . Over the upper Danube catchment (Germany only), the mean areal rain was $75.7 \mathrm{~mm}$ compared to 62.5 and $111.2 \mathrm{~mm}$ in 2002 and 1954, respectively.

The most striking feature in 2002 was the extreme precipitation over the Ore Mountains reaching values of $312 \mathrm{~mm}$ in the $24 \mathrm{~h}$ before 13 August 2002, 06:00 UTC, at the station of Zinnwald-Georgenfeld (Ulbrich et al., 2003). The R3d totals (Fig. 4, middle) show a larger area at the eastern parts of the Ore Mountains with values in excess of $300 \mathrm{~mm}$. However, additional high rain totals were only observed at the southern border of Bavaria as well as over the Swabian Jura. This distribution is mainly caused by northerly flow in conjunction with a so-called $\mathrm{Vb}$ weather situation (Ulbrich et al., 2003). Comparable to the 2013 event, flood-triggering precipitation occurred with a shift of 2 days between the southern and eastern parts of Germany that correspond to the Danube and Elbe catchments, respectively (Fig. 5, middle). Note that the regions with larger temporal differences in the occurrence of R3d maxima are not associated with high amounts of precipitation (see Fig. 4). Application of extreme value statistics to R3d totals yields return periods of more than 200 years for the maxima. Return periods around 100 years are estimated for the lowlands north of the Ore Mountains (Fig. 6, middle). Precipitation in that region also contributed to the large increase in runoff of the Elbe.

In 1954, most parts of Bavaria experienced 3-day accumulated rainfalls in excess of $150 \mathrm{~mm}$ (Fig. 4, right). This was even the case for the lowlands in the north of Bavaria. Near the Alps as well as over the western parts of the Ore Mountains, R3d reached values of $300 \mathrm{~mm}$ or even more. These extreme totals recorded within a time shift of only 1 day (Fig. 5, right) correspond to statistical return periods of more 

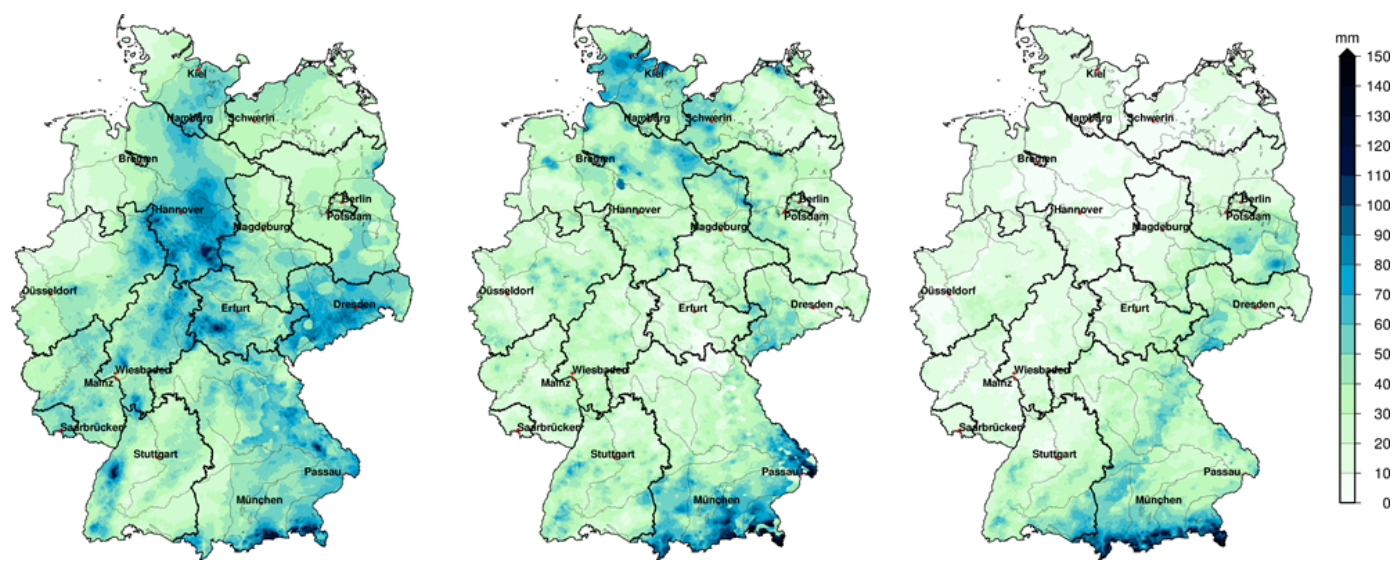

Figure 7. Antecedent precipitation index (API) over 30 days for the floods in June 2013 (left), August 2002 (middle) and July 1954 (right). See text for further details.
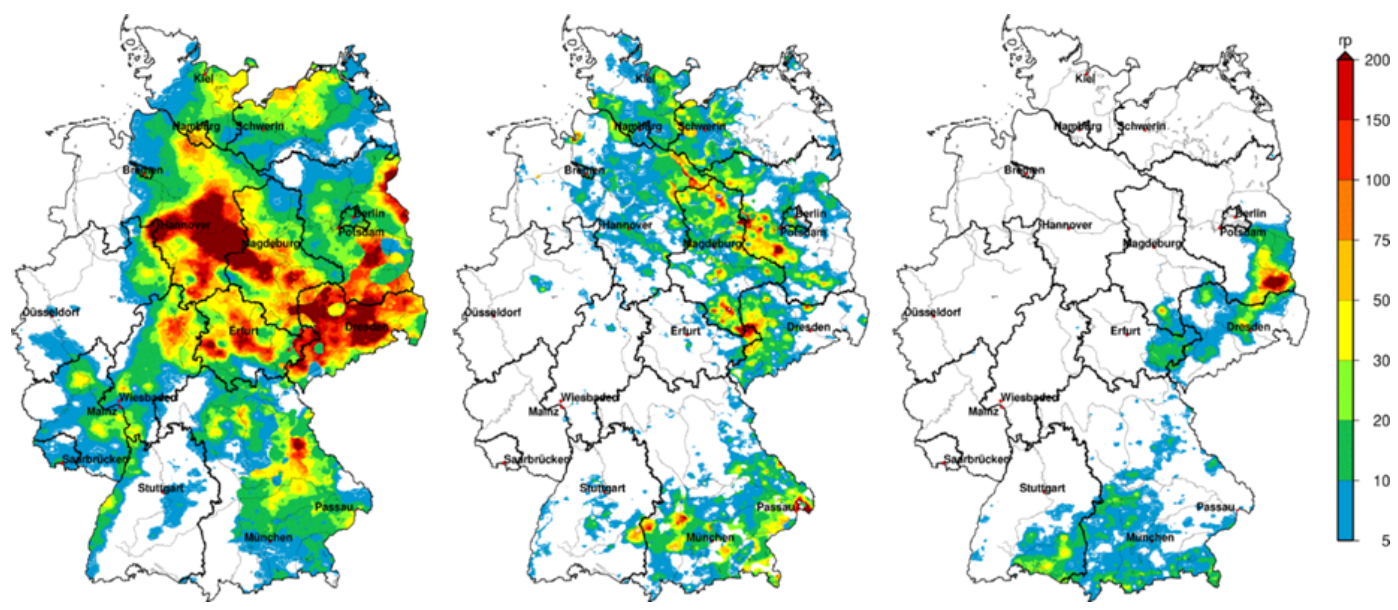

Figure 8. Return periods of the API displayed in Fig. 7 derived from 30-day API of large-scale floods in the period from 1960 to 2009 : June 2013 (left), August 2002 (middle) and July 1954 (right).

than 200 years covering more than half of Bavaria (Fig. 6, right). Thus, considering only the observed precipitation directly prior to the onset of the flooding, 1954 was certainly the most extreme event that occurred within the last 60 years.

The same conclusions can be drawn when considering 7day instead of 3-day maxima (see Fig. A2 in the Appendix). Of course, the rain totals increase for the longer accumulation period, for example over the Ore Mountains in 2013 or in Bavaria for 2002. The estimated return periods, especially in the Elbe and Danube catchments, are less affected by these changes - with the exception of an area in the north of Munich, where return periods in excess of 100 years can be identified for June 2013. Note that the high return periods for 7-day precipitation totals in June 2013 which are visible in Northwest Bavaria are related to the Rhine catchment (see Fig. A1).

\subsection{Initial catchment state}

\subsubsection{Antecedent precipitation}

In the next step, we assess initial catchment wetness by means of the antecedent precipitation index (API). This proxy is based on the starting date of R3d (day of the year shown in Fig. 5 minus 3 days) and computed independently at each grid point of REGNIE. API reached high values between $100 \mathrm{~mm}$ and in excess of $150 \mathrm{~mm}$ over large parts of Germany, especially - and most importantly - over the catchments of Elbe and Danube (Fig. 7, left). At a large number of grid points, especially in the upper Elbe catchment, the return periods are between 100 and 200 years, at some points even in excess of the latter (Fig. 8, left). Note that the maximum that occurred between Hanover and Magdeburg was related to considerable flooding at the Aller, Oker and Leine rivers in the Weser catchment for which no discharge data were available. The high rain totals in the month of May, especially 

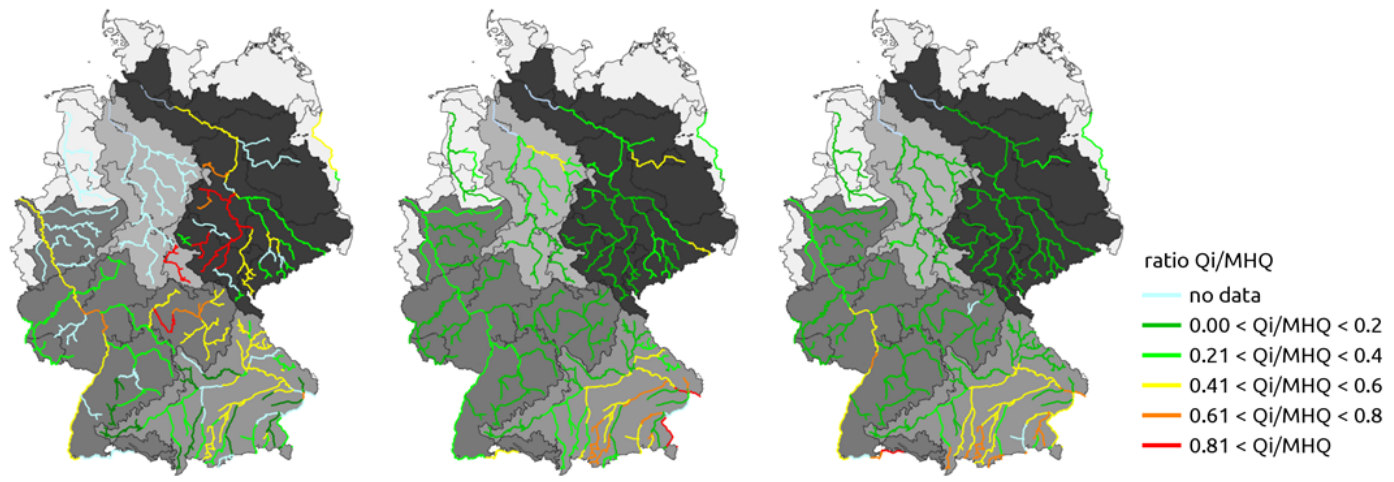

Figure 9. Initial flow ratio at meteorological event start $Q_{\mathrm{i}}$ normalized for MHQ (calculated from AMS 1950-2009) for June 2013 (left), August 2002 (middle) and July 1954 (right).

those at the end of May (recall the increasing weighting of rain totals in API with decreasing temporal distance to R3d), resulted in very wet catchments and filling of storage capacities and thus very favourable conditions for high runoff coefficients.

Regarding the initial moisture conditions, it is found that API was significantly lower prior to the floods in 1954 and 2002, respectively (Fig. 7). In both cases, high values of API up to $150 \mathrm{~mm}$ can be observed only over parts of the Bavarian Alps related to orographic precipitation induced by northerly flow directions. Whereas in 2013 the maxima of API correspond well with those of R3d, this is not the case for the two other events. Especially over the Ore Mountains and north of them, where highest rainfall was observed, API was below $50 \mathrm{~mm}$ in both cases, yielding return periods below 20 years at most of the grid points (Fig. 8). The same applies to the API in the Danube catchment in 1954. Both in 2002 and 1954 high API values indicate that the initial wetness was comparatively high, but in general not in those regions where the event precipitation was highest (compare Fig. 4 and Fig. 7). Apart from areal precipitation as described above, this is the major difference to the 2013 event.

\subsubsection{Initial hydraulic load}

As a consequence of the large amounts of rainfall accumulated during the month of May, reflected by the extended areas of high API, also the initial hydraulic load in the river network was already clearly increased at the beginning of the event precipitation in 2013. In general, the pattern of increased initial hydraulic load in the rivers shown in Fig. 9 (left) resembles the spatial distribution of high API values (Fig. 7, left). This mostly applies to the central and southeastern parts of Germany. Most prominent in this regard were the Saale River and its tributaries Wipper and Bode in the western part of the Elbe catchment with an initial flow ratio above 0.8 of MHQ. The Rhine, upper Main, Danube, with tributaries Naab and Isar and the Werra River were also affected. Note that for many gauges in the Weser and lower
Rhine catchments no discharge data are available for the June 2013 flood (see Fig. A1 in the Appendix for geographic locations).

In comparison, for the August 2002 and July 1954 floods the initial hydraulic load of the river network was clearly lower with few exceptions (Fig. 9). In August 2002, basically the Danube and its tributaries Inn, Isar, Lech and Regen showed a noticeable increase of initial river discharge (ca. 0.5 of MHQ). These catchments showed also high API values. Similarly, at the beginning of the July 1954 flood increased river discharges of about 0.4 to 0.8 of MHQ for the Danube and its southern tributaries are visible. Also the middle and upper parts of the Rhine show increased initial hydraulic loads in this range. The lower coincidence of regions of increased initial hydraulic load with regions of increased API for the July 1954 flood (compare Fig. 7 and 9) suggests that the increased initial hydraulic load particularly along the Rhine was induced by different mechanisms than high amounts of antecedent precipitation, presumably due to snow-melt in the alpine headwaters of the Rhine.

From the statistical extreme value analysis applied to the $Q_{\mathrm{i}} / \mathrm{MHQ}$ samples at each gauge we obtain an estimate for the return period of the specific initial river flow situation for the June 2013, August 2002 and July 1954 floods. The results presented in Fig. 10 show that for the June 2013 flood the initial flow ratios observed in central Germany, in particular at the upper Main (Rhine catchment), Werra (Weser catchment), Wipper, Saale, Weiße Elster, Mulde (Elbe catchment) and Naab and Vils (Danube catchment), exhibit return periods in the range of 10-50 years, in some river stretches even above 100 years. For the events in August 2002 and July 1954 comparable extremes are only observed for few river stretches in the Danube catchment including the Regen, upper Isar, Ilz, Inn and Salzach rivers in 2002 and the upper Iller, Lech and Isar rivers in 1954.

The initial hydraulic load of the river network $(13400 \mathrm{~km})$ was clearly increased in June 2013 given the comparison to other large-scale flood events from the last 50 years. Hence, 

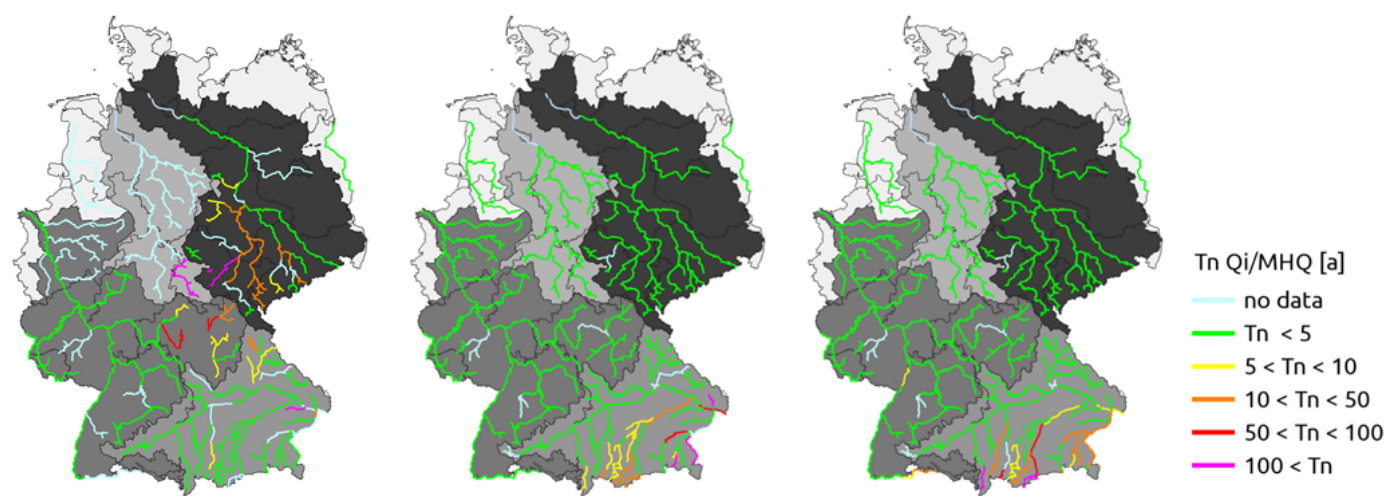

Figure 10. Return periods of initial flow ratio at meteorological event start ( $Q_{\mathrm{i}}$ normalized for MHQ) derived from $Q_{\mathrm{i}} / \mathrm{MHQ}$ ratios of large-scale floods in the period from 1969 to 2009: June 2013 (left), August 2002 (middle) and July 1954 (right).
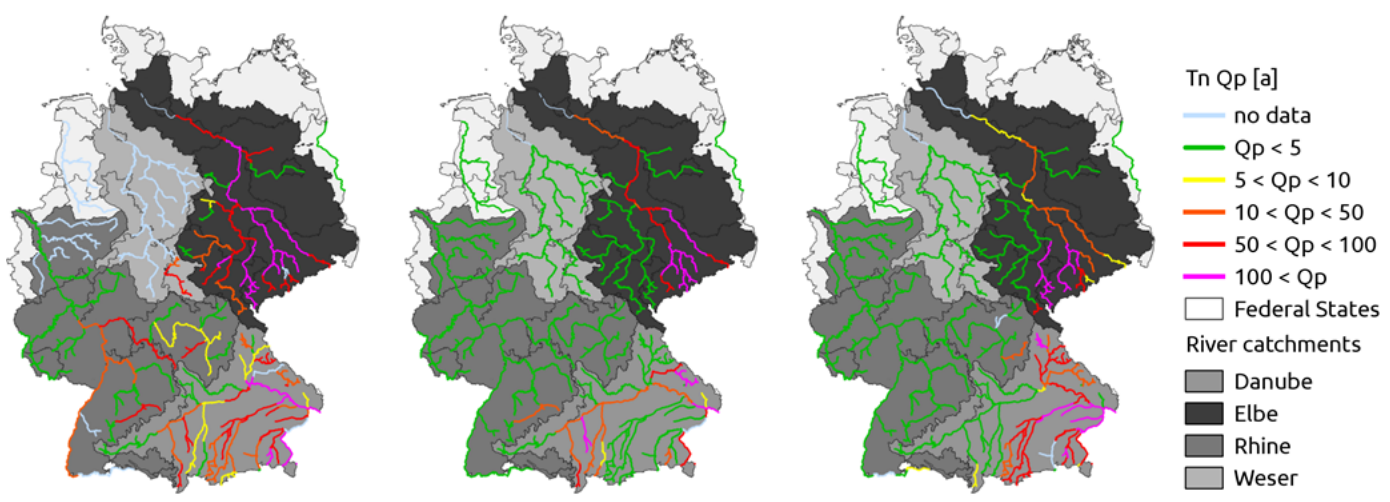

Figure 11. Regionalized return periods (Tn) of flood peak discharges for June 2013 (left), August 2002 (middle) and July 1954 (right). Gauge data were made available by the Water and Shipping Management of the Fed. Rep. (WSV) prepared by the Federal Institute for Hydrology (BfG) and environmental state offices of the federal states.

the aggravating effect of increased initial hydraulic load was stronger in June 2013 than in August 2002 and July 1954. However, extraordinarily high initial flow ratios occurred only in some river stretches, namely the Saale River and its tributaries.

\subsection{Peak flood discharges}

In June 2013, $45 \%$ of the total river network considered in Germany showed peak discharges above a 5-year flood. As can be seen in Fig. 11 (left), all major catchments showed flooding, namely the Weser, Rhine, Elbe and Danube catchments. Particularly the Elbe and Danube rivers and many of their tributaries were affected by extraordinarily high flood levels. In the Elbe catchment, flood peak discharges exceeded a return period of 100 years along the whole Elbe stretch between Dresden and Wittenberge (Brandenburg), the Mulde, and the tributaries of the Saale River, Weiße Elster and Ilm. In the Danube catchment, the section of the Danube downstream of Regensburg as well as the Inn and Salzach rivers experienced peak discharges with return periods above 100 years. In addition, the Isar, Naab and Iller rivers showed flood peaks above 50-year return periods. Further, in the Rhine catchment, the Neckar and parts of the Main as well as the Werra River in the Weser catchment experienced peak discharges above the 50 year return period. New record water levels were registered at the Elbe between Coswig and Lenzen (along a total length of $250 \mathrm{~km}$ ), at the Saale downstream of Halle, and at the Danube in Passau. Severe flooding occurred especially along the Danube and Elbe rivers, as well as along the Elbe tributaries Mulde and Saale, in most cases as a consequence of dike breaches. It is remarkable that large parts of catchments affected by flooding did not receive exceptional amounts of rain (see Fig. 4). In particular, this applies to the upstream parts of the Saale, Werra and Main catchments. However, these regions show high amounts of antecedent precipitation and substantial initial hydraulic load.

The August 2002 and July 1954 floods show peak discharges in the order of 100-year return periods at the Elbe between Dresden and Wittenberg (Saxony-Anhalt), in parts of the Mulde, Regen and Mindel and of 50 years at the Freiberger and Zwickauer Mulde and the Elbe downstream 
Table 2. Severity indices for June 2013, August 2002 and July 1954 floods.

\begin{tabular}{lrrr}
\hline & June & August & July \\
Index & 2013 & 2002 & 1954 \\
\hline Precipitation index $\left(S_{\mathrm{R} 3 \mathrm{~d}}\right)$ & 16.9 & 30.1 & 55.2 \\
Wetness index $\left(S_{\mathrm{API}}\right)$ & 114.1 & 47.3 & 21.1 \\
Initial hydraulic load index $\left(S_{Q_{\mathrm{i}}}\right)$ & 12.7 & 6.0 & 6.1 \\
Flood severity index $\left(S_{Q_{\mathrm{p}}}\right)$ & 74.6 & 35.4 & 49.8 \\
\hline
\end{tabular}

of Wittenberg (Saxony-Anhalt) to Wittenberge (Brandenburg) (see Fig. 11, middle and right panels). In July 1954 return periods of 100 years occurred at the Weiße Elster and Mulde in the Elbe catchment and the Isar, Rott and Inn in the Danube catchment. Flood peaks with a return period of 50 years were observed at the Danube-downstream Regensburg, the Naab, Inn and Salzach as well as the upper Isar rivers. However, as can be seen in Fig. 11 (middle and right), the river stretches with high-magnitude flood peaks are clearly less extended in August 2002 and July 1954: the index $L$ describing the spatial flood extent amounts to $19 \%$ in August 2002, $27 \%$ in July 1954 and $45 \%$ in June 2013 (see Fig. A1 in the Appendix for geographic locations).

The major differences of the flood in June 2013 in comparison to August 2002 and July 1954 are that the Elbe, the Mulde and the Saale rivers were affected simultaneously by extraordinary flooding which by superposition of flood waves resulted in unprecedented flood levels particularly in the middle part of the Elbe. Further, nearly all tributaries of the Danube showed flood responses and jointly contributed to the record flood along the Danube downstream of Regensburg. Also the Rhine and Weser catchments were considerably affected even though the magnitude of the peak discharges was not as extreme as in the Elbe and Danube catchments.

\subsection{Index-based classification}

We evaluate the importance of the individual hydrometeorological factors within the different flood events using the severity indices introduced in Sect. 2.3. The precipitation-, wetness-, initial hydraulic load- and flood severity indices enable us to compare the 74 past large-scale flood events with regard to the spatial extent and magnitude of each hydro-meteorological factor. This allows for the identification of singularities in terms of extreme situations associated with individual events. The index values for the June 2013, August 2002 and July 1954 events are listed in Table 2.

Among these events, the June 2013 flood is characterized by the highest wetness, initial hydraulic load and flood severity indices which are more than twice the values of the August 2002 flood and with regard to wetness more than five times the value of the July 1954 flood. In contrast, the precipitation index of July 1954 exceeds the value of June 2013 by a factor of 3 and is nearly twice as high as for the August 2002 event. These proportions emphasize the prominent role of extreme antecedent precipitation and increased initial hydraulic load in the river network as key factors for the formation of the extreme flood in June 2013.

Figure 12 shows a scatterplot of the precipitation and wetness indices of the 74 past large-scale floods in Germany. The June 2013 flood is the most extreme in terms of the wetness index, whereas the July 1954 flood is by far the most extreme in terms of the precipitation index. To explore the relationship between precipitation and wetness indices as flood drivers and the flood severity index as dependent variable, we apply a locally weighted scatterplot smooth (LOWESS) model (Cleveland, 1979). For this locally weighted linear least-squares regression, the tri-cube weight function and a span of $50 \%$ are used. The span specifies the percentage of data points that are considered for estimating the response value at a certain location. The performance of the LOWESS model to explain the variation of flood severity is expressed in terms of root mean square error (RMSE) which can be interpreted as the standard deviation of unexplained variance.

The inclined orientation of the response surface indicates that both precipitation and wetness are equally relevant factors to explain resulting flood severity. According to this model, flood severity index values above around 0.5 (normalized values) increase approximately proportionate with precipitation and wetness severity. However, both the concave shape of the response surface, visible for precipitation and wetness index values below 0.5 (normalized values), and the moderate performance of the LOWESS model to explain variability of flood severity (RMSE $=13.2)$ suggest that additional factors and characteristics influence this relationship. The spatial variability and the corresponding degree of areal overlaps of the factors as well as other hydrological processes, for instance snow melt or seasonal variations in base flow, play a role in this regard.

\subsection{Sensitivity Analysis}

To check the robustness of our evaluation of the flood in June 2013, it is important to revisit the specifications of parameters of the methodology. Besides, depending on the focus of the analysis the use of different return periods as reference levels for the assessment of severity may be of interest. We examine the implication of varying duration of event precipitation and antecedent precipitation index period as well as different values for the depletion constant for the calculation of API, as well as different return periods as reference levels for the calculation of severity indices following a one-ata-time sensitivity analysis design (Saltelli et al., 2000). The scenarios examined are listed in Table 3. To assess the implications of these variations on the evaluation of the flood events, we are interested in the changes in the ranking of the flood events with regard to different severity indices. For this purpose, we compare the reference set-up which has been 

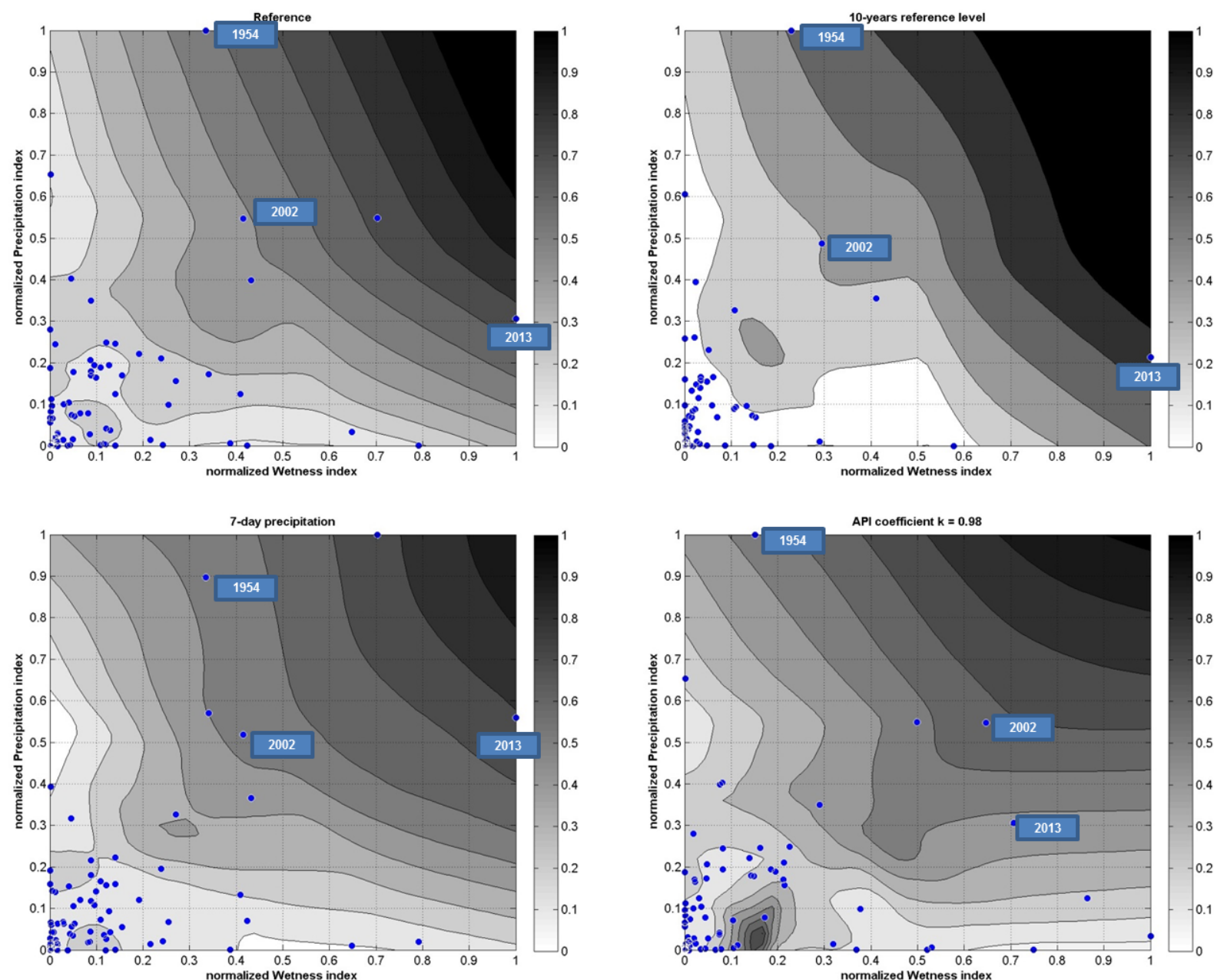

Figure 12. Locally weighted scatterplot smooth (LOWESS) model for the relationship between precipitation and wetness indices as predictors for the flood severity index (grey colour code) of past large-scale flood events in Germany. Top left: Reference (5-year return period as reference level for severity indices, R3d, API 30 days, $k=0.9$ ); top right: 10-year return period as reference level for severity indices; bottom left: R7d; bottom right: API k0.98. Note that all severity indices have been normalized to the respective maximum values and that the upper right corners do not contain observed data.

Table 3. Variation scenarios examined within sensitivity analysis.

\begin{tabular}{lccc}
\hline Scenario & Code & Reference & Variation \\
\hline Duration event precipitation & R7d & 3 days & 7 days \\
Duration antecedent precipitation & API15 & 30 days & 15 days \\
Depletion constant API & API k0.8 & $k=0.9$ & $k=0.8$ \\
& API k0.98 & $k=0.9$ & $k=0.98$ \\
Return period reference level flood severity & S10a & 5 years & 10 years \\
& S25a & 5 years & 25 years \\
Return period reference level precipitation severity & P10a & 5 years & 10 years \\
& P25a & 5 years & 25 years \\
Return period reference level wetness severity & W10a & 5 years & 10 years \\
& W25a & 5 years & 25 years \\
Return period reference level initial hydraulic load severity & I10a & 5 years & 10 years \\
& I25a & 5 years & 25 years \\
\hline
\end{tabular}




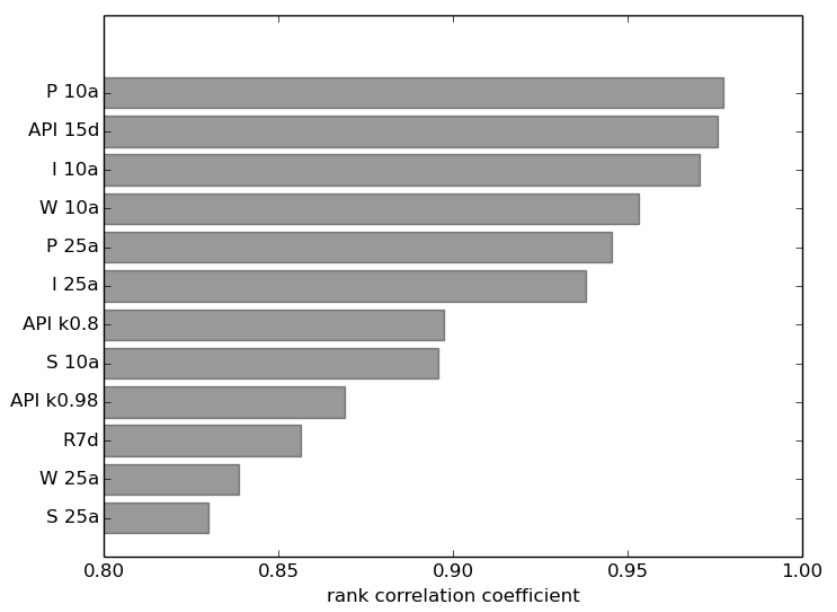

Figure 13. Spearman's rank correlation coefficients between the reference scenario and the variations examined within the sensitivity analysis; for the scenario definition see Table 3.

used to introduce the methodology to the outcomes from the different variations in terms of Spearman's rank correlation coefficient $(\rho)$. Lower rank correlations mean larger differences in the outcomes and indicate a larger sensitivity to these variations.

The implications of these variations are moderate. The correlation coefficients between the reference scenario and these variations are above 0.83 (see Fig. 13). The most sensitive variations are related to changing the return periods used as reference level for the calculation of flood severity and wetness severity indices to 25 years (S25a and W25a). This is followed by duration of event precipitation (R7d) and increasing the depletion constant, i.e. the weight of earlier precipitation within the calculation of API (API k0.98). We track the implications on the outcomes of the LOWESS model for these variations (see Fig. 12 bottom left and right panels for R7d and API k0.98). Further, we examine the changes in LOWESS model outcome for the variation of return periods used as reference level for the calculation of severity indices, i.e. 10 and 25 years. Increasing the return period used as reference level for the calculation of severity indices implies a reduced range of precipitation or discharge observations, and hence, an increased focus on local extremes. For the 25year level this leads to a pronounced clustering of precipitation and wetness index values below 5 (not shown). Exceptions are the floods in July 1954, August 2002 and June 2013. Using a 10-year return period as reference level the scattering of data points is also low resulting in a less welldefined model for precipitation indices below 0.3 (normalized values) and wetness indices below 0.2 (normalized values, Fig. 12 top right panel). The interpolated surface indicates a stronger inclination towards the wetness index which suggests that flood severity increases disproportionately with catchment wetness. Varying the duration of event precipitation to 7 days (R7d) shifts the attention to events which are more related to west cyclonic circulation patterns, and thus is rather associated with winter floods (Beurton and Thieken, 2009) but also with the autumn flood in October 1998 (Uhlemann et al., 2014). Accordingly, the October 1998 flood yields the highest precipitation severity index in Fig. 12 (bottom left panel). The increase of the depletion coefficient $k$ within API corresponds to an almost equal weighting of the precipitation over the antecedent precipitation period. As a result three floods achieve higher wetness indices than the flood in June 2013 even though the flood severity of these events is clearly lower. According to the resulting LOWESS model interpolation (see Fig. 12 bottom left panel) the importance of catchment wetness for flood severity is reduced.

Overall, across the variation scenarios examined the relationship between precipitation and wetness indices as flood drivers and the flood severity index as dependent variable is largely comparable. The floods of July 1954, August 2002 and June 2013 remain among the most severe events and mainly determine the shape of the LOWESS model response surface in the region of high severity indices. Hence, the main finding of the index-based classification which points out that both precipitation and wetness are equally relevant factors to explain flood severity remains valid.

\section{Conclusions}

This study provides new insights into the characteristics of hydro-meteorological factors that caused the flood in June 2013 and presents a statistical evaluation of the associated return periods. The data-based approach further comprises aggregated index values which consider both the spatial extent and magnitudes of the different hydro-meteorological factors and allows for the comparison to past and future largescale flood events. The results of this analysis proved robust against variations in parameters within the calculation procedure. The large-scale flood database and the methodological framework developed enable the rapid assessment of future floods based on precipitation and discharge observations.

The results illustrate that the sequence of prevalent circulation patterns in May 2013 introduced an important boundary condition for the extraordinary precipitation anomaly observed. For this flood, diverse hydro-meteorological factors showed exceptional characteristics.

First, the development of event precipitation and in particular the substantial orographic rainfall enhancement was driven by a very low lifting condensation level in combination with high amounts of precipitable water in the atmosphere. This was continuously sustained by the strong influx of high water vapour resulting from a strong and persistent flow of air from the north to northeast.

Second, during the weeks before the onset of the flood, enormous amounts of antecedent precipitation occurred over large parts of Germany. As the areas of high antecedent and event precipitation were amply overlapping, the wet initial 
conditions strongly intensified the runoff response to event precipitation. Hence, particularly the large areal superposition and interplay of event precipitation and wet initial catchment conditions proved to be key drivers for the exceptional hydrological severity of the flood in June 2013. In the Saale catchment the increased initial hydraulic load in the river network was an additional aggravating factor. In the Danube, the movement of the event precipitation field from west to east, i.e. following the streamflow direction, amplified the superposition of the flood waves from the tributaries.

Third, the spatial extent of high-magnitude flood peaks marks a new record for large-scale floods in Germany for at least the last 60 years and set new record water levels along extensive river sections in Germany.

In comparison, the flood in August 2002 was triggered in Germany by extremely intense precipitation which was relatively localized in the Ore Mountains. Initial wetness showed considerably high values in some parts of Germany but these areas did not coincide largely with event precipitation. The flooding in July 1954 was for the main part caused by exceptional amounts of event precipitation affecting large parts of Bavaria. In comparison to August 2002 and June 2013, initial wetness was a less important factor in Germany. However, at the northern ridge of the Alps initial wetness contributed to flood generation in the Salzach and Inn rivers (Blöschl et al., 2013).
Our results show that the influence of catchment wetness is a considerable factor for high-return period, large-scale floods in Germany. In this regard we support the hypothesis that hydrological extremes are rather a consequence of unusual combinations of different hydro-meteorological factors than of unusual magnitudes of the factors themselves as stated by Klemes (1993). Using the knowledge gained about the characteristics, the range of magnitudes and interactions of the various hydro-meteorological factors associated with large-scale floods from the past 60 years, we can advance the derivation of plausible extreme scenarios. In this regard, the database compiled for large-scale floods in Germany may be analysed concerning the possibilities of coinciding extremes of individual hydro-meteorological factors, as for instance the combination of initial wetness observed in June 2013 and event precipitation as in July 1954. Of course, the development of such scenarios requires an in-depth analysis of synoptic meteorological situations and the corresponding transition of related weather conditions. The hydrological evaluation of such extreme scenarios could provide new insights for large-scale flood hazard assessment, planning scenarios for national disaster response, spatial risk as well as cumulated flood losses. These insights may find further use in advanced approaches for flood frequency analysis and design flood estimation (e.g. Merz and Blöschl, 2008; Paquet et al., 2013). 


\section{Appendix A}

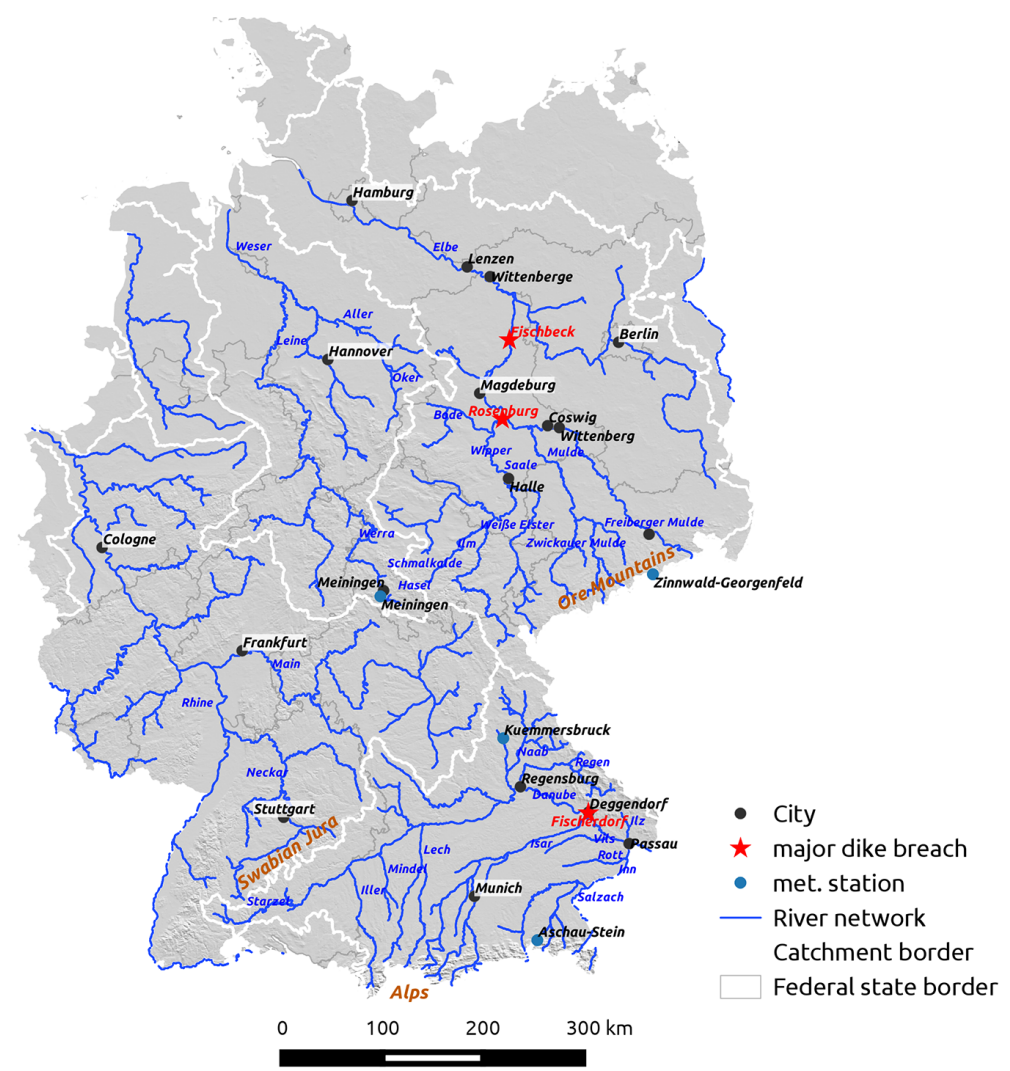

Figure A1. Outline map of geographic locations referred to in the text.
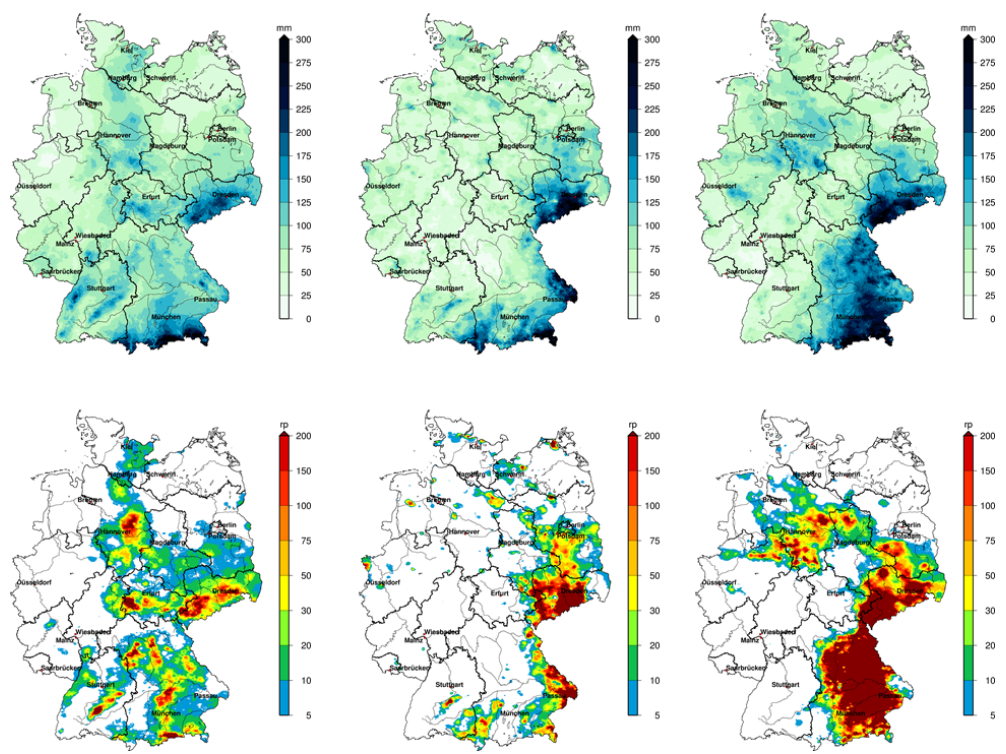

Figure A2. As Figs. 4 and 6, but for 7-day maximum precipitation (top line: 7-day maximum precipitation; bottom line: return periods June 2013, left; August 2002, middle; July 1954, right). 
Acknowledgements. We thank Michel Lang, Christian Reszler, Massimiliano Zappa and two anonymous referees for their thoughtful comments and helpful suggestions to improve the paper.

The study was undertaken and financed under the framework of CEDIM - Center for Disaster Management and Risk Reduction Technology. We gratefully thank the German Weather Service (DWD) for providing REGNIE data, Bavarian State Office of Environment (LfU), Baden-Württemberg Office of Environment, Measurements and Environmental Protection (LUBW), Brandenburg Office of Environment, Health and Consumer Protection (LUGV), Saxony State Office of Environment, Agriculture and Geology (SMUL), Saxony-Anhalt Office of Flood Protection and Water Management (LHW), Thüringen State Office of Environment and Geology (TLUG), Hessian Agency for the Environment and Geology (HLUG), Rhineland Palatinate Office of Environment, Water Management and the Factory Inspectorate (LUWG), Saarland Ministry for Environment and Consumer Protection (MUV), Office for Nature, Environment and Consumer Protection North Rhine-Westphalia (LANUV NRW), Lower Saxony Office for Water Management, Coast Protection and Nature Protection (NLWKN), Water and Shipping Management of the Fed. Rep. (WSV), prepared by the Federal Institute for Hydrology (BfG) who provided discharge data.

The service charges for this open access publication have been covered by a Research Centre of the Helmholtz Association.

Edited by: N. Ursino

\section{References}

Ahmed, N. U.: Estimating soil moisture from $6 \cdot 6 \mathrm{GHz}$ dual polarization, and/or satellite derived vegetation index, Int. J. Remote Sens., 16, 687-708, doi:10.1080/01431169508954434, 1995.

Alfieri, L., Pappenberger, F., and Wetterhall, F.: The extreme runoff index for flood early warning in Europe, Nat. Hazards Earth Syst. Sci., 14, 1505-1515, doi:10.5194/nhess-14-1505-2014, 2014.

Beurton, S. and Thieken, A.: Seasonality of floods in Germany, Hydrol. Sci. J., 54, 62-76, doi:10.1623/hysj.54.1.62, 2009.

BfG: Länderübergreifende Analyse des Juni Hochwassers 2013, Bundesanstalt für Gewässerkunde, Deutscher Wetterdienst, Koblenz, 2013.

Blanchard, B. J., McFarland, M. J., Schmugge, T. J., and Rhoades, E.: Estimation of Soil Moisture with Api Algorithms and Microwave Emission1, JAWRA J. Am. Water Resour. Assoc., 17, 767-774, doi:10.1111/j.1752-1688.1981.tb01296.x, 1981.

Blöschl, G., Nester, T., Komma, J., Parajka, J., and Perdigão, R. A. P.: The June 2013 flood in the Upper Danube Basin, and comparisons with the 2002, 1954 and 1899 floods, Hydrol. Earth Syst. Sci., 17, 5197-5212, doi:10.5194/hess-17-5197-2013, 2013.

CEDIM: June 2013 Flood in Central Europe - Focus Germany Report 1 - Update 2: Preconditions, Meteorology, Hydrology, Center for Disaster Management and Risk Reduction Technology, Potsdam, available at: http://www.cedim.de/download/ FDA_Juni_Hochwasser_Bericht1-ENG.pdf, last access: 17 October, 2013a.
CEDIM: June 2013 Flood in Central Europe - Focus Germany Report 2 - Update 1: Impact and Management, Center for Disaster Management and Risk Reduction Technology, Potsdam, available at: http://www.cedim.de/download/ FDA-Juni-Hochwasser-Bericht2-ENG.pdf, last access: 17 October, 2013b.

Chow, V. T.: Open-channel hydraulics, McGraw-Hill., New York, NY, USA, 710 pp., 1959.

Cleveland, W. S.: Robust Locally Weighted Regression and Smoothing Scatterplots, J. Am. Stat. Assoc., 74, 829-836, doi:10.2307/2286407, 1979.

Deutscher Bundestag: Bericht zur Flutkatastrophe 2013: Katastrophenhilfe, Entschädigung, Wiederaufbau, 2013.

Duckstein, L., Bárdossy, A., and Bogárdi, I.: Linkage between the occurrence of daily atmospheric circulation patterns and floods: an Arizona case study, J. Hydrol., 143, 413-428, doi:10.1016/0022-1694(93)90202-K, 1993.

DWD: Deutschlandwetter im Frühling 2013, Wetter Klima Dtsch. Wetterd. - Presse, available at: http://www.dwd.de/bvbw/ generator/DWDWWW/Content/Presse/Pressemitteilungen/ 2013/20130529_DeutschlandwetterimFruehling, templateId=raw, property=publicationFile.pdf/20130529_ DeutschlandwetterimFruehling.pdf, last access: 6 June 2013.

Embrechts, P., Klüppelberg, C., and Mikosch, T.: Modelling Extremal Events - for Insurance and Finance, Springer, Berlin, Heidelberg, available at: http://www.springer.com/mathematics/ quantitative+finance/book/978-3-540-60931-5 (last access: 20 June 2014), 1997.

Ettrick, T. M., Mawdlsey, J. A., and Metcalfe, A. V.: The influence of antecedent catchment conditions on seasonal flood risk, Water Resour. Res., 23, 481-488, doi:10.1029/WR023i003p00481, 1987.

GDV: Erste Schadenbilanz: Hochwasser 2013 verursacht 180.000 versicherte Schäden in Höhe von fast 2 Milliarden Euro, available at: http://www.presseportal.de/pm/39279/2505807/, last access: 2 July 2013.

Grams, C. M., Binder, H., Pfahl, S., Piaget, N., and Wernli, H.: Atmospheric processes triggering the central European floods in June 2013, Nat. Hazards Earth Syst. Sci., 14, 1691-1702, doi:10.5194/nhess-14-1691-2014, 2014.

Klemes, V.: Probability of extreme hydrometeorological events a different approach, in: Extreme Hydrological Events: Precipitation, Floods and Droughts, IAHS, Yokohama, 213, 167-176, 1993.

Köhler, M. A. and Linsley, R. K., Jr.: Predicting runoff from storm rainfall, US Weather Bureau, Washington, D.C., p. 9, 1951.

Kron, W.: Zunehmende Überschwemmungsschäden: Eine Gefahr für die Versicherungswirtschaft?, DCM, Meckenheim, Würzburg, 47-63, 2004.

Kunz, M.: Characteristics of Large-Scale Orographic Precipitation in a Linear Perspective, J. Hydrometeorol., 12, 27-44, doi:10.1175/2010JHM1231.1, 2011.

Merz, R. and Blöschl, G.: A process typology of regional floods, Water Resour. Res., 39, 1340, doi:10.1029/2002WR001952, 2003.

Merz, B. and Plate, E. J.: An analysis of the effects of spatial variability of soil and soil moisture on runoff, Water Resour. Res., 33, 2909-2922, doi:10.1029/97WR02204, 1997. 
Merz, B., Elmer, F., Kunz, M., Mühr, B., Schröter, K. and Uhlemann-Elmer, S.: The extreme flood in June 2013 in Germany, Houille Blanche, 1, 5-10, doi:10.1051/lhb/2014001, 2014.

Merz, R. and Blöschl, G.: Flood frequency hydrology: 1. Temporal, spatial, and causal expansion of information, Water Resour. Res., 44, W08432, doi:10.1029/2007WR006744, 2008.

Munich Re: Natural Catastrophes 2013 Analyses, assessments, positions, Munich Re, Munich, 65 pp., 2013.

Nied, M., Hundecha, Y., and Merz, B.: Flood-initiating catchment conditions: a spatio-temporal analysis of large-scale soil moisture patterns in the Elbe River basin, Hydrol. Earth Syst. Sci., 17, 1401-1414, doi:10.5194/hess-17-1401-2013, 2013.

Paquet, E., Garavaglia, F., Garçon, R., and Gailhard, J.: The SCHADEX method: A semi-continuous rainfall-runoff simulation for extreme flood estimation, J. Hydrol., 495, 23-37, doi:10.1016/j.jhydrol.2013.04.045, 2013.

Perry, M. A. and Niemann, J. D.: Analysis and estimation of soil moisture at the catchment scale using EOFs, J. Hydrol., 334, 388-404, doi:10.1016/j.jhydrol.2006.10.014, 2007.

Rauthe, M., Steiner, H., Riediger, U., Mazurkiewicz, A., and Gratzki, A.: A Central European precipitation climatology Part I: Generation and validation of a high-resolution gridded daily data set (HYRAS), Meteorol. Z., 22, 235-256, doi:10.1127/0941-2948/2013/0436, 2013.

Reager, J. T., Thomas, B. F., and Famiglietti, J. S.: River basin flood potential inferred using GRACE gravity observations at several months lead time, Nat. Geosci., 7, 588-592, doi:10.1038/ngeo2203, 2014

Saltelli, A., Chan, K., and Scott, E. M.: Sensitivity Analysis, John Wiley \& Sons Ltd, Chichester, UK, 475 pp., 2000.

Smith, R. B. and Barstad, I.: A Linear Theory of Orographic Precipitation, J. Atmospheric Sci., 61, 1377-1391, doi:10.1175/15200469(2004)061< 1377:ALTOOP> 2.0.CO;2, 2004.

Van Steenbergen, N. and Willems, P.: Increasing river flood preparedness by real-time warning based on wetness state conditions, J. Hydrol., 489, 227-237, doi:10.1016/j.jhydrol.2013.03.015, 2013.

Strahler, A. N.: Quantitative analysis of watershed geomorphology, Trans. Am. Geophys. Union, 38, 913-920, doi:10.1029/TR038i006p00913, 1957.
Swiss Re: Sigma preliminary estimates: natural catastrophes and man-made disasters in 2013 cost insurers worldwide USD 44 billion, Prelim. Catastr. Estim. 2013 Swiss Re - Lead. Glob. Reinsur, available at: http://www.swissre.com/media/news_releases/ nr_20131218_sigma_natcat_2013.html, last access: 18 December 2013.

Teng, W. L., Wang, J. R., and Doraiswamy, P. C.: Relationship between satellite microwave radiometric data, antecedent precipitation index, and regional soil moisture, Int. J. Remote Sens., 14, 2483-2500, doi:10.1080/01431169308904287, 1993.

Thieken, A. H., Müller, M., Kreibich, H., and Merz, B.: Flood damage and influencing factors: New insights from the August 2002 flood in Germany, Water Resour. Res., 41, 1-16, doi:10.1029/2005WR004177, 2005.

Troch, P. A., Smith, J. A., Wood, E. F., and de Troch, F. P.: Hydrologic controls of large floods in a small basin: central Appalachian case study, J. Hydrol., 156, 285-309, doi:10.1016/0022-1694(94)90082-5, 1994.

Uhlemann, S., Thieken, A. H., and Merz, B.: A consistent set of trans-basin floods in Germany between 1952-2002, Hydrol. Earth Syst. Sci., 14, 1277-1295, doi:10.5194/hess-14-12772010, 2010.

Uhlemann, S., Thieken, A. H., and Merz, B.: A quality assessment framework for natural hazard event documentation: application to trans-basin flood reports in Germany, Nat. Hazards Earth Syst Sci., 14, 189-208, doi:10.5194/nhess-14-189-2014, 2014.

Ulbrich, U., Brücher, T., Fink, A. H., Leckebusch, G. C., Krüger, A., and Pinto, J. G.: The central European floods of August 2002: Part 1 - Rainfall periods and flood development, Weather, 58, 371-377, doi:10.1256/wea.61.03A, 2003.

Viessman, W. and Lewis, G. L.: Introduction to Hydrology, 5th edition., Prentice Hall, New York, USA, 612 pp., 2002. 